2015-11-01

\title{
Determination of Nanoparticle Localisation Within Subcellular Organelles in Vitro Using Raman Spectroscopy
}

\author{
Esen Efeoglu \\ Technological University Dublin \\ Mark Keating \\ Technological University Dublin \\ Jennifer McIntyre \\ Technological University Dublin
}

See next page for additional authors

Follow this and additional works at: https://arrow.tudublin.ie/biophonart

Part of the Biological and Chemical Physics Commons

\section{Recommended Citation}

"Determination of Nanoparticle Localisation within Subcellular Organelles in vitro using Raman Spectroscopy", Esen Efeoglu, Mark Keating, Jennifer Mclntyre, Alan Casey, Hugh J. Byrne, Analytical Methods, 7, 10000-10017 (2015). doi:10.1039/C5AY02661J

This Article is brought to you for free and open access by the DIT Biophotonics and Imaging at ARROW@TU Dublin. It has been accepted for inclusion in Articles by an authorized administrator of ARROW@TU Dublin. For more information, please contact arrow.admin@tudublin.ie, aisling.coyne@tudublin.ie,gerard.connolly@tudublin.ie. Funder: SFI 


\section{Authors}

Esen Efeoglu, Mark Keating, Jennifer McIntyre, Alan Casey, and Hugh Byrne

This article is available at ARROW@TU Dublin: https://arrow.tudublin.ie/biophonart/21 


\title{
Determination of Nanoparticle Localisation within Subcellular Organelles in vitro using Raman Spectroscopy
}

\author{
Esen Efeoglu ${ }^{1,2, *}$, Mark Keating ${ }^{1,2}$, Jennifer McIntyre $^{2}$, Alan Casey $^{2}$, Hugh J. Byrne $^{2}$ \\ ${ }^{1}$ School of Physics, Dublin Institute of Technology, Kevin Street, Dublin 2, Ireland \\ ${ }^{2}$ FOCAS Research Institute, Dublin Institute of Technology, Kevin Street, Dublin 2, Ireland \\ *Corresponding Author: esen.efeoglu@mydit.ie
}

\begin{abstract}
Ease of sample preparation, narrow spectral bandwidth and minimal influence from water are features of Raman spectroscopy which make it a powerful, label-free way to study a wide range of biological structures and phenomena. In this context, given the concerns over their toxicology arising from their increased production and use, evaluation of nanoparticle uptake and localisation in biological systems and determination of the mechanisms of subcellular interaction and trafficking can provide long-term solutions for nanotoxicology, and potential strategies for nanomedicine. In this study, Raman spectroscopy is explored to monitor the sequential trafficking of nanoparticles through subcellular organelles in-vitro and to establish the spectroscopic signatures of those organelles. A549 human lung carcinoma cells were exposed to $40 \mathrm{~nm}$ carboxylate-modified and fluorescently-labelled polystyrene nanoparticles for 4, 12 and 24hrs. Raman spectroscopy was applied to nanoparticle exposed cells to determine the localisation within cellular compartments. Confocal laser scanning fluorescence microscopy (CLSM) with different organelle staining kits confirmed the localisation of the nanoparticles in organelles at the chosen exposure periods and colocalization was quantified using ImageJ with the JACoP colocalisation plugin. To confirm nanoparticle localisation and elucidate the spectroscopic signatures of the different
\end{abstract}


subcellular organelles, a combination of K-means clustering (KMCA) and Principal components analysis (PCA) was applied to the Raman spectroscopic maps. The study showed the applicability of the techniques for elucidation of the localisation of polystyrene nanoparticles within the cell as well as determination of their local environment, differentiating the spectral signatures of intracellular compartments such as endosomes, lysosomes and endoplasmic reticulum, in a completely label free manner.

Keywords: Nanotoxicology, Nanomedicine, Raman spectroscopy, in vitro screening, subcellular localisation, Label free imaging 


\section{Introduction}

Increased production and extended use of nanomaterials in different application areas, from composites to cosmetics, has highlighted the necessity of evaluation of every aspect of their biological interactions. Although nanostructures and nanostructured tools have been considered in recent years to be suitable for medical applications, challenges remain, such as blood circulation time and targeting efficiency. Furthermore, despite the undeniable potential of these particles, questions remain concerning their toxicity which has restricted their widespread use in medicine and has created the subcategory of toxicology, known as 'Nanotoxicology'. Nanotoxicology deals with the potential risks and adverse health effects that can arise from nanomaterial use and aims to achieve safe deployment of nanotechnologies ${ }^{2}$. The physicochemical properties of nanoparticles such as the size and the shape of nanoparticles, surface area and surface chemistry can determine the potential risk of the material. Besides physico-chemical determinants, molecular level determinants can be considered as a different aspect of nanotoxicology. Nanoparticles may induce the formation of Reactive Oxygen Species (ROS) and expression of inflammatory markers ${ }^{3,4}$. The production of ROS, due to their high chemical activity, can cause destruction of DNA, carbohydrates, proteins and lipids ${ }^{5}$. The destruction of DNA and proteins causes a genotoxic response which may cause DNA adduct formation, DNA damage, chromosomal aberration, mutation, apoptosis and finally cell death ${ }^{6,7}$. The possible routes of exposure and biodistribution of nanoparticles also effect their toxicity ${ }^{8,9}$. The consideration of nanotoxicity therefore needs to take into account realistic exposure scenarios, and regulatory government agencies must work with the colloboration of academia and industry ${ }^{10,11}$. A detailed understanding of the interaction of engineered nanoparticles with tissues, cells and bodily fluids is also of great importance for optimisation in medical applications such as drug delivery, molecular imaging and tissue implants. 
Intracellular trafficking of nanoparticles, ROS production and inflammatory responses have been widely studied (see for example the review by Nel et al., $2009^{11}$ ). Endocytosis is accepted as the primary mechanism for the cellular uptake of nanoparticles into cells ${ }^{12}$. Subsequently, nanoparticles are trafficked through endosomes and later lysosomes ${ }^{13,14}$. Although it has been studied extensively, the complexity of the process and varied physicochemical properties of nanoparticles still raise question marks on this issue. For this reason, direct visualization of the uptake of nanoparticles and observation of their trafficking within the cell is of critical importance to develop routine toxicological screening protocols and novel tools for nanomedicine.

The tracking of nanomaterials, from the initial exposure of cells to nanomaterials, to exocytosis or degradation has been studied by microscopic and spectroscopic techniques ${ }^{15-17}$. Electron microscopy (EM) has also been used for the visualisation of nanoparticles in cells. However, not all nanoparticles are visible by EM within the cellular environment, and sample preparation can furthermore cause alteration on the structure of cells ${ }^{13,18}$. Standard optical microscopy can be used for the visualization of cells. Although it is possible to image live cells, it is difficult to gain detailed information about subcellular structures due to the limited spatial resolution. Nanoparticles which have been labeled by fluorescent dyes have been extensively studied and Confocal Laser Scanning Microscopy (CLSM) is an invaluable tool for the visualization of nanoparticles for in vitro studies ${ }^{19-22}$. By the use of these fluorescent based techniques, fluorescent emmission of nanoparticles and the subcellular location of nanoparticles have been determined. Two photon exitation techniques and NIR fluorophores can increase the penetration depths of the detection techniques ${ }^{23-26}$. Using fluorescent based techniques, it is also possible to observe physological processes within a cell. The labeling of lysosomes and mitochondria can be achieved by using lyso and mitotracker which are available as commercial kits $^{27}$. Although these techniques allow visualization of the 
nanoparticles in vitro and determination of their localisation in the cell, they have drawbacks. Fluorescent based microscopy is limited in resolution and all nanoparticles cannot be functionalized with flourescent dyes. Moreover, labeled nanoparticles may release the dye into the local environment from their surfaces such that the detection of fluorescence does not guarantee the presence of nanoparticles ${ }^{12,15,26}$.

Spectroscopic techniques have also been studied for the visualisation of cellular and subcellular structures of cells ${ }^{15-17,28,29}$. In particular, vibrational spectroscopic techniques such as Infrared absorption (IR) and Raman spectroscopy have been widely used for the localisation studies of nanoparticles ${ }^{28,30-32}$. Although IR spectroscopy can provide important information about the localisation of nanoparticles inside the cell, its limited spatial resolution can be a problem. Another challenge of the technique for biological samples is water, which gives strong signals in IR spectra ${ }^{33}$. As an alternative vibrational spectroscopic technique, Raman spectroscopy has been demonstrated to be a powerful technique to study different biolomolecules and biomolecular structures ${ }^{34}$. Due to the ease of sample preparation, narrow spectral bandwidths and minimal influence from water, the technique can be used for biological samples and the optical wavelengths commonly employed render it particularly suitable for subcellular analysis ${ }^{35}$. Label-free imaging of live cells has been studied by Klein et al., by combining immunofluorescence (IF) imaging with Raman spectroscopy to identify cellular structures such as nucleus, cytoplasm and cellular organelles $^{37}$. Also, coregistration of flourescence images with Raman images has been studied by Krauss et al. $^{37}$. The study by Dorney et. al. shows the ability of Raman spectroscopy to observe nanopaparticles in intracellular compartments as well as the b1ochemical responses and information from their subcellular environment based on their intrinsic spectroscopic signatures which makes the technique completely label free ${ }^{15}$. Moreover, different supervised and unsupervised data mining techniques such as spectral 
cross correlation and classical least squares (CLS) analysis have been used by Keating et al. to extract cellular information directly from complex Raman data sets in the presence of nanoparticles ${ }^{16}$.

This study extends the work of Dorney et al. ${ }^{15}$ and Keating et al. $^{16}$, which demonstrated the ability of Raman spectroscopy to localise polystyrene nanoparticles in cells after a $24 \mathrm{hr}$ exposure, to monitor the evolution of the intracellular environment of nanoparticles as they are progressively trafficked through the different subcellular organelles of the cell, from $4 \mathrm{hrs}$ to $24 \mathrm{hrs}$ exposure, and further demonstrate the potential of Raman spectroscopic imaging as a truly label free, high content analysis technique, by establishing the spectroscopic signatures of these subcellular organelles. Nontoxic, $40 \mathrm{~nm}$ carboxylated and flourescently labelled polystyrene nanoparticles were used as a model nanoparticles to show the applicability of Raman Spectroscopy as an analytical tool to determine particle localisation within subcellular compartments and establish the spectral fingerprint of these compartments. Nontoxic particles were chosen in order to minimise the perturbation to the cell metabolism, and the nontoxic nature of the particles was confirmed using conventional cytotoxicity assays. CLSM and Raman Spectroscopy were applied to polystyrene nanoparticles and their localisation was determined within cell compartments at different exposure times. A549 human lung carcinoma cells were chosen as a model cell line and cells were exposed to nanoparticles for 4, 12 and $24 \mathrm{hrs}$. Confocal images with different cell compartment staining kits was used to confirm their localisation at different exposure times and quantification of co-localisation were made by using ImageJ and the JACoP colocalisation plugin. Raman mapping was applied for unlabelled single cells and Raman datasets were analyzed by using unsupervised K-means clustering (KMCA) and principal components (PCA) analysis. The applicability of Raman Spectroscopy was assessed for the 
determination of the characteristic spectra of subcellular organelles in which nanoparticles are enveloped and trafficked in a comletely label free manner.

\section{Materials and Methods}

\subsection{Nanoparticles}

Commercially available, $40 \mathrm{~nm}$ carboxylate-modified and fluorescently labelled polystyrene nanoparticles (F8795) were purchased from Invitrogen (USA). The characteristic properties such as size and emission spectra are supplied by Invitrogen ${ }^{38}$ and have been further characterised in house using a Malvern Zetasizer ZS for size and surface potential measurements, Atomic Force microscopy (AFM) and UV-Vis spectroscopy ${ }^{39}$.

\subsection{Cell Culture and Cytotoxicity}

A549 cells from human lung carcinoma (ATCC number CCL-185) were chosen as a model cell line in this study. Cells were cultured in Dulbecco's Modified Eagle's Medium Nutrient Mixture F-12 HAM (DMEM-F12) with $2 \mathrm{mM}$ L-glutamine and 10\% foetal bovine serum (FBS) at $37{ }^{\circ} \mathrm{C}$ in $5 \% \mathrm{CO}_{2}$. DMEM-F12 cell culture medium and trypsination solution were purchased from Sigma Aldrich, Ireland. For cytotoxicity evaluation, commonly used Alamar Blue (AB) and 3-(4,5-dimethylthiazol-2-yl)-2,5-diphenyltetrazolium bromide (MTT) assays were purchased from Biosource (UK) and Sigma Aldrich Ltd. (Dublin, Ireland), respectively. Details about cytotoxicity assay and results are given in Supplementary Information (SI.1).

\subsubsection{Preparation of nano-polystyrene solutions}

Polystyrene nanoparticle solutions were prepared by dispersing nanoparticles directly into the 10\% FBS and $2 \mathrm{mM}$ L-glutamine supplemented DMEM-F12 medium. The initial stock 
concentration of the polystyrene nanoparticle solution was chosen as $1 \times 10^{12}$ particles per $\mathrm{ml}$ (ppml).

\subsection{Confocal Laser Scanning Fluorescence Microscopy}

\subsubsection{Sample Preparation for Confocal Microscopy}

Samples for CLSM were prepared by seeding approximately 16,000 A549 cells onto $35 \mathrm{~mm}$ uncoated glass bottom dishes purchased from MatTek Corporation, USA. For effective adherence of the cells on the glass surface, $200 \mu \mathrm{l}$ of cell suspension at a density of 16,000 cells were dropped onto the glass surface and incubated for $1 \mathrm{hr}$. Following $1 \mathrm{hr}$ incubation, 2 ml of DMEM-F12 medium with 10\% FBS and 2mM L-glutamine were added, and the cells were incubated for $24 \mathrm{hrs}$. After $24 \mathrm{hr}$ incubation, the medium was removed and nanoparticles suspended in medium (DMEM-F12 with 10\% FBS and 2mM L-glutamine) were added. For all confocal imaging studies, nanoparticle suspensions of concentration $1 \times 10^{12} \mathrm{ppml}$ were used. In order to determine the time evolution of the subcellular localisation of nanoparticles, 4, 12 and $24 \mathrm{hrs}$ exposure times were chosen. Following exposure, the medium containing nanoparticles was removed and the cells were rinsed with PBS and the samples were imaged in sterile $0.9 \% \mathrm{NaCl}$ saline solution.

\subsubsection{Confocal Fluorescence Imaging of Cell Compartments}

Lysotracker (Red DND-99), Endoplasmic Reticulum (ER)-Tracker and Cell Light Early Endosome-RFP Bacmam 2.0 stains were purchased from Life Technologies, Ireland. All organelle stains were prepared according to manufacturer's instructions. $200 \mu \mathrm{l}$ of A549 cells suspension at a density of 16,000 cells were seeded onto the glass bottom dishes and cells were incubated for $1 \mathrm{hr}$. After initial attachment, $2 \mathrm{ml}$ of DMEM-F12 medium with supplements were added. The cells were incubated overnight at $37{ }^{\circ} \mathrm{C}$ in $5 \% \mathrm{CO}_{2}$. The culture 
medium was then removed and the cells were exposed to the nanoparticle solution of concentration $1 \times 10^{12} \mathrm{ppml}$ for 4, 12 and $24 \mathrm{hrs}$. For Lysotracker and ER stains, the effective concentrations used were $75 \mathrm{nM}$ and $1 \mu \mathrm{M}$, respectively, according to manufacturer instructions, and probes were diluted to final concentrations from their stocks. Medium, containing nanoparticles, was removed from the dishes and the pre-warmed $\left(37^{\circ} \mathrm{C}\right)$ medium containing the cellular stains was added separately. Cells were then incubated for $30 \mathrm{~min}$ at $37{ }^{\circ} \mathrm{C}$ in $5 \% \mathrm{CO}_{2}$. After incubation, the stain containing medium was removed and the dishes were rinsed with PBS three times. Confocal images were captured in sterile pre-warmed PBS saline solution. For endosomal staining, cells were seeded onto the glass bottom dishes with the same density with other staining and $2 \mathrm{ml}$ of DMEM-F12 medium was added following the initial attachment. After 24 hour, cells were exposed to CellLight Reagent BacMam 2.0RFP for $16 \mathrm{hrs}$ at $37^{\circ} \mathrm{C}$ for expression of Red fluorescent protein. Cells were exposed to the polystyrene particles prepared in pre-warmed medium at $37{ }^{\circ} \mathrm{C}$ with a concentration of $1 \times 10^{12}$ ppml for 4 hours. After 4 hr particle exposure, cells were washed three times with PBS and observed in PBS.

For confocal imaging of nanoparticles and organelles within the cell, an inverted Zeiss LSM510 Meta, confocal laser scanning microscope (Carl Zeiss Inc.) equipped with a x60 oil immersion objective and Argon (488 nm) and $\mathrm{HeNe}(543 \mathrm{~nm})$ lasers was used to determine the localisation of polystyrene nanoparticles within cell compartments. Table 1 lists the absorption and emission characteristics for the target species.

A 505-530 nm band pass filter was used to collect the fluorescence of $40 \mathrm{~nm}$ carboxylated and fluorescently labelled polystyrene nanoparticles. In order to observe nanoparticle localisation within intracellular compartments, images were acquired by using the combination of a 505-530 $\mathrm{nm}$ band pass filter to collect the fluorescence of nanoparticles and a $560 \mathrm{~nm}$ long pass filter for the organelle staining dye fluorescence. Analysis of images was 
carried out using LSM 510 software and quantification of colocalisation was calculated using the JACoP colocalisation plugin with ImageJ.

Table 1. Spectral Characteristics of $40 \mathrm{~nm}$ carboxylated and fluorescently labelled polystyrene nanoparticles and organelle probes.

\begin{tabular}{|c|c|c|}
\hline Organelle Probes & Abs*(nm) & Em*(nm) \\
\hline $\begin{array}{c}\text { 40 nm carboxylated- } \\
\text { nanoparticles }\end{array}$ & 505 & 515 \\
\hline Lysotracker®Red DND-99 & 577 & 590 \\
\hline ER-Tracker ${ }^{\text {TM }}$ & 587 & 615 \\
\hline $\begin{array}{c}\text { Cell Light }{ }^{\circledR} \text { Early Endosome- } \\
\text { RFP Bacmam 2.0 }\end{array}$ & 543 & 560 \\
\hline
\end{tabular}

\subsection{Raman Spectroscopy}

\subsubsection{Sample preparation for Raman Spectroscopy}

To prepare samples for Raman spectroscopic analysis, approximately 16,000 cells per substrate were seeded on $\mathrm{CaF}_{2}$ slides and they were incubated for 24 hrs in $2 \mathrm{mls} 10 \% \mathrm{FBS}$ DMEM - F12 medium at $37{ }^{\circ} \mathrm{C}$ in $5 \% \mathrm{CO}_{2}$. After $24 \mathrm{hrs}$, the medium was removed and 40 nm polystyrene nanoparticles suspended in 10\% FBS DMEM - F12 media were added. A549 cells were exposed to the nanoparticles for 4,12 and 24 hrs. A concentration of $1 \times 10^{12} \mathrm{ppml}$ was used for $24 \mathrm{hr}$ exposure. The exposure time affects the degree of uptake of nanoparticles, aggregate formation and thus the intensity of the characteristic Raman bands of polystyrene 
nanoparticles, and therefore doses of $5 \times 10^{12} \mathrm{ppml}$ were chosen to achieve clearer spectra for earlier exposure times. Following nanoparticle exposure, cells were rinsed three times with PBS and fixed with $10 \%$ formalin for $10 \mathrm{~min}$. Cells were washed with water to remove formalin and spectra were acquired in water.

In this study, a Horiba Jobin-Yvon LabRAM HR800 spectrometer equipped with a $785 \mathrm{~nm}$ diode laser was used. All measurements were acquired by using a x100 water immersion objective (LUMPlanF1, Olympus, N.A. 1), producing a spotsize on the sample of $\sim 1 \mu \mathrm{m}$. Before spectral acquisition, the system was calibrated to the $520.7 \mathrm{~cm}^{-1}$ line of silicon. A 300 lines per mm grating (approximately $1.5 \mathrm{~cm}^{-1}$ per pixel spectral dispersion) and a $100 \mu \mathrm{m}$ confocal pinhole were used throughout this study. The spectra were dispersed onto a 16-bit dynamic range Peltier cooled CCD detector. All white-light images of the cells were taken by using the integrated video camera. Raman maps were acquired over selected areas. Spectra were acquired for $2 \times 10$ seconds per spot, to achieve acceptable signal to noise ratios. The spectral range was chosen from 400 to $1800 \mathrm{~cm}^{-1}$. The step size between two measurements was set to $1 \mu \mathrm{m}$ for all exposure times.

\subsection{Data Analysis}

Unsupervised KMCA and PCA were performed on different Raman data sets by using Matlab (Mathworks, USA) in order to extract information from complex and huge datasets. Data pre-processing was also carried out using Matlab. First, mild smoothing by using a Savitsky-Golay filter (3th order, 9 points) was applied to lightly smooth the data. The background, predominantly water in the immersion geometry, was subtracted with unsupervised Classical Least Squares (CLS) analysis to minimize the possible background contributions into the spectra ${ }^{34}$. Following smoothing and background subtraction, spectra were vector normalized before analysis to improve spectral quality. 
KMCA, considered the simplest unsupervised learning algorithm, was used as a first step of spectral map analysis. It is a spectral image analysis technique which uses the similarities in the spectra to form clusters; each representing the specific biomolecular signature of a selected area. Briefly, in KMCA, the number of clusters (k) is defined a priori by the operator to initialize the classification. K centroids were formed by the programme randomly but as far as possible from each other and then each point around centroids is associated the nearest point on data set for initial classification. Following initial classification, barycentres are formed by rearranging the first centroids and the process continues until convergence is reached and there is no further change in the centroids. The final k-means clusters and associated mean spectra give information about molecular similarities within data sets and can be used to differentiate regions with different molecular features.

For further analysis, PCA was employed to examine and differentiate the spectral characteristics of specific k-means clusters. Thus, PCA was used to highlight the changes on the biochemical composition based on nanoparticle exposure which may clarify the mode of interaction and particle localisation with cells. Specifically, the loadings of the PC were used to identify and differentiate the spectroscopic signatures of the different cell compartments in which the nanoparticles are localised, including early endosomes, lysosomes and endoplasmic reticulum.

\section{Results and Discussion}

\subsection{Nanoparticle Cytotoxicity}

In advance of further analysis, the cytotoxicity of the polystyrene nanoparticles to the cells over the range of doses and exposure times employed was examined using standard cytotoxic 
assays, as described in the Supplemental Material (S1). Consistent with previous reports for neutral and carboxylated polystyrene particles ${ }^{15}$, no significant cytotoxicity was recorded.

\subsection{Confocal Laser Scanning fluorescence microscopy}

Because the uptake of nanoparticles within a cell population is a continuous process, it is possible to observe the progressive trafficking through different cell compartments as a function of incubation time. The intracellular localisation of particles as a function of nanoparticle exposure time was examined using CLSM. Cells were exposed to a dose of $1 \times 10^{12}$ ppml of media for 4, 12 and $24 \mathrm{hrs}$. Localisation of fluorescently labelled and carboxylated polystyrene nanoparticles in the perinuclear region of A549 cells after $24 \mathrm{hr}$ particle exposure has previously been shown by Dorney et. al. ${ }^{15}$.

In order to determine the localisation of nanoparticles in a more specific manner, organelle staining kits were used to further examine the localisation environment for $24 \mathrm{hrs}$ and earlier exposure times. Cells were exposed to $40 \mathrm{~nm}$ carboxylated and fluorescently labelled polystyrene nanoparticles for 24, 12 and $4 \mathrm{hrs}$. Following the incubation period, the medium was removed, cells were washed with PBS thrice and cells were incubated with $1 \mu \mathrm{M}$ Endoplasmic Reticulum staining and $75 \mathrm{nM}$ Lysotracker for $30 \mathrm{~min}$. For early endosome staining, cells were exposed to CellLight BacMam 2.0 reagent for $16 \mathrm{hrs}$ at $37^{\circ} \mathrm{C}$ after initial $24 \mathrm{hr}$ incubation. After incubation with the organelle staining agents, cells were washed with PBS and observed in $\mathrm{NaCl}$ solution.

To demonstrate the amount of co-localisation of the nanomaterial within the different subcellular compartments, fluorescent images of polystyrene particles and organelle staining and their overlay images were recorded for each incubation time. An example of the images taken for each exposure time and organelle staining are shown in Figure 1 and Figure 2. These images were then used to quantify the degree of co-localization of polystyrene 
nanoparticles and cellular compartments. The overall calculation of colocalisation coefficients was made based on the average of 3 images for each particle exposure time and organelle staining.

Figure 1 shows the CLSM images of A549 cells after 24 and $12 \mathrm{hr}$ particle exposure (green) with Lysosome and Endoplasmic Reticulum staining (red). Co-localisation is indicted by yellow/orange colouring. The confocal images of $40 \mathrm{~nm}$ carboxylated polystyrene particles indicate that, although some of the particles localise in the lysosomes after $24 \mathrm{hr}$ incubation (Figure 1A), the nanoparticles are predominantly associated with endoplasmic reticulum at this time point (Figure 1B). On the other hand, as seen in Figure 1C, when the exposure time of A549 cells to the polystyrene particles is reduced to $12 \mathrm{hrs,} \mathrm{most} \mathrm{of} \mathrm{the} \mathrm{particles} \mathrm{are}$ observed in the lysosomes and, there is less co-localization with the ER at this time point (Figure 1D). The small amount of co-localisation in lysosomes at the $24 \mathrm{hr}$ time point and the ER at the $12 \mathrm{hr}$ time point demonstrates the continuity of the trafficking process. 


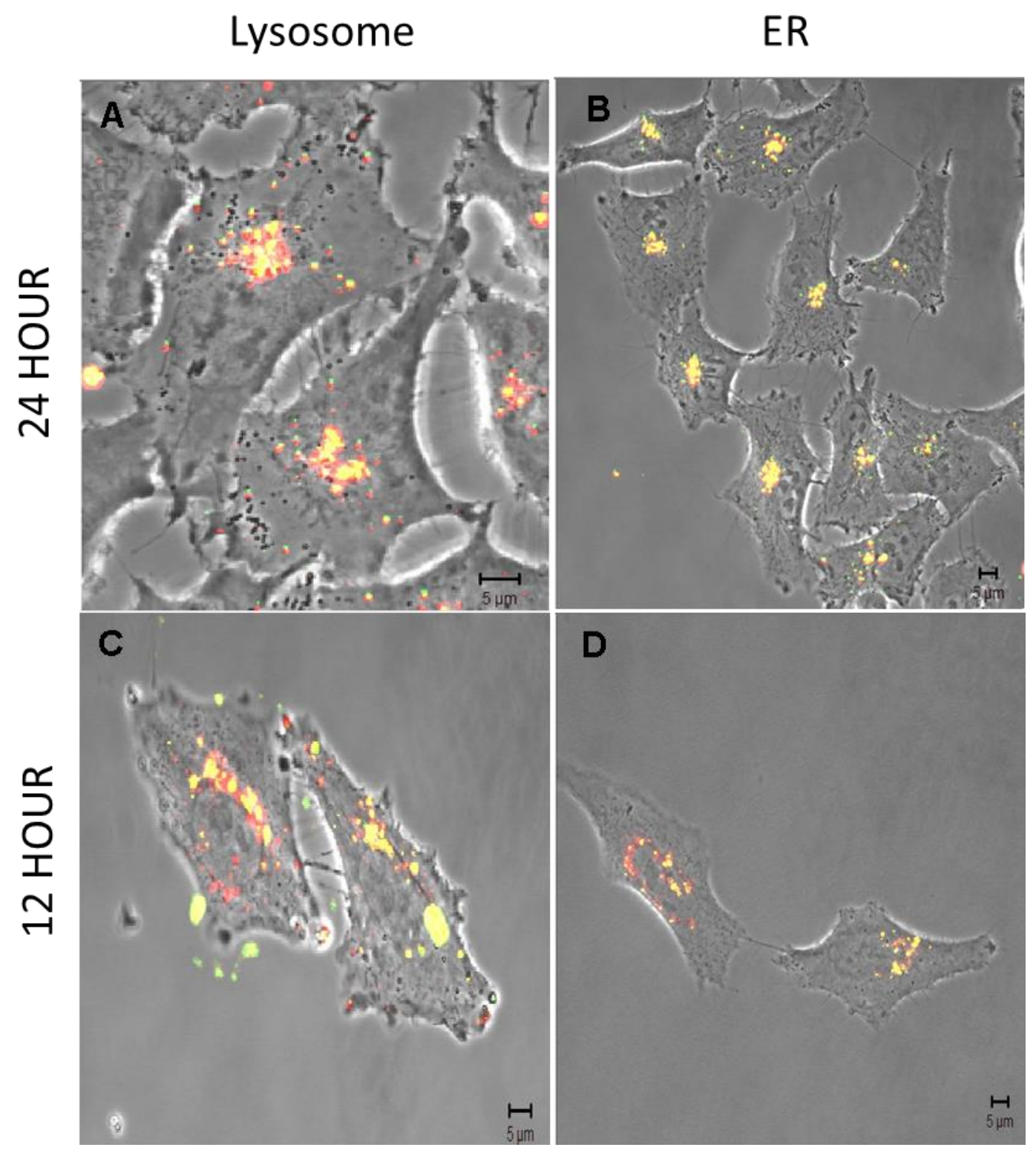

Figure 1. Confocal Images of $40 \mathrm{~nm}$ carboxylated polystyrene nanoparticles (green) and lysosomes (red) of A549 cells after 24 hours (A) and 12 hours (C), confocal images of 40nm carboxylated polystyrene nanoparticles (green) and endoplasmic reticulum (red) of A549 cells after 24 hours (B) and 12 hours (D) x60 magnification. Co-localisation is indicated by yellow/orange. 
After $4 \mathrm{hr}$ exposure, the nanoparticles are seen to be more diffusely distributed throughout the cytoplasm, as shown in Figure 2. Figure 2A shows some degree of co-localization with lysosomes, whereas Figure 2B demonstrates that there is a significantly higher amount of colocalization in endosomes.
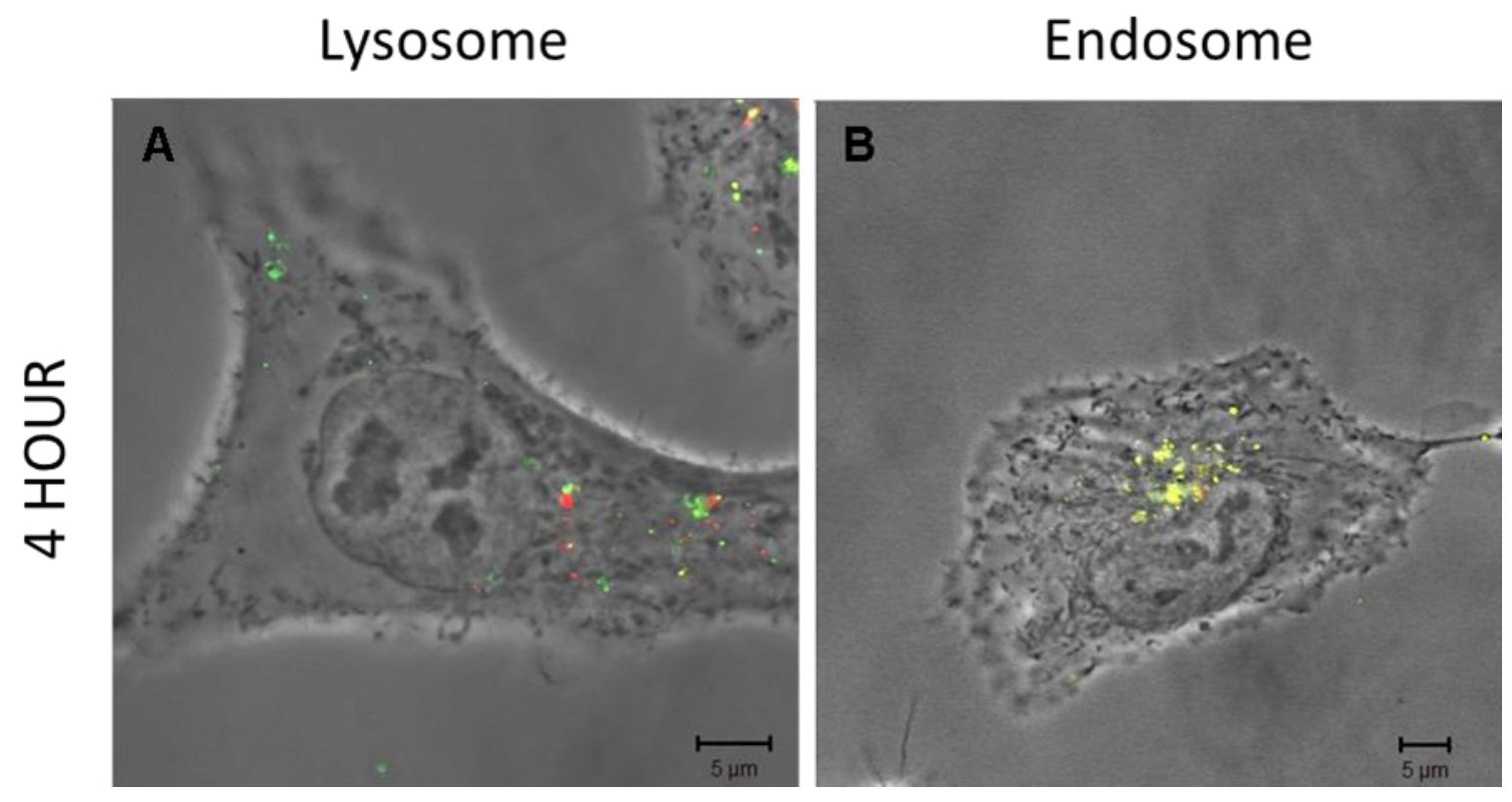

Figure 2. Confocal Images of 40nm carboxylated polystyrene nanoparticles (green) and lysosomes (red) of A549 cells after 4 hours (A), confocal images of 40nm carboxylated polystyrene nanoparticles (green) and early endosome stain (red) of A549 cells after 4 hours (B) x60 magnification. Co-localisation is indicated by yellow/orange.

Quantification of the degree of subcellular organelle colocalisation at the chosen exposure periods was performed by using the JACoP plugin of Image ${ }^{40}$. The quantification of colocalization relies on the estimation of overlay in stained sections with at least two different fluorescent dyes. In the current study, the multicolour confocal microscopic images of green fluorescent polystyrene particles and organelle staining kits were used to obtain quantitative amount of overlay. Even though co-localization can be due to the close physical proximity of different labelled species, it can clarify the common localisation points for nanoparticles 
within the cell. The preparation steps, image acquisition and pre-process of images play an important role in achieving a precise quantification of co-localisation. Therefore, all acquired images were subjected to background correction. Co-localisation coefficients were calculated for background corrected images. Pearson's coefficient and Mander's coefficients were used to calculate the quantitative amount of co-localisation. As seen in Table 2, 90\% of early endosomes contain polystyrene nanoparticles after $4 \mathrm{hr}$ exposure. When cells are exposed to the nanoparticles, all particles are not taken up by cell at the same time. Therefore, $52 \%$ of lysosomes contain polystyrene nanoparticles at the same incubation time. $72 \%$ of lysosomes are associated with nanoparticles after $12 \mathrm{hr}$ incubation, while, when cells were exposed to nanoparticles for $24 \mathrm{hrs}$, this amount was reduced to $53 \%$. On the other hand, the amount of endoplasmic reticulum which contains nanoparticles was calculated as 58\% after $12 \mathrm{hr}$ incubation, whereas this amount increased to $80 \%$ after $24 \mathrm{hrs}$.

Table 2. Quantification of Co-localisation of Nanoparticles with Cellular Structures.

\begin{tabular}{|c|c|c|c|c|c|}
\hline & $\begin{array}{c}\text { Exposure } \\
\text { Time(hr) }\end{array}$ & $\begin{array}{c}\text { Pearson } \\
\text { Coefficient(r) }\end{array}$ & $\begin{array}{c}\text { Overlap } \\
\text { Coefficient(R) }\end{array}$ & $\mathbf{k}_{1} \& \mathbf{k}_{2}$ & $\begin{array}{c}\text { Mander's } \\
\text { Coefficient(M) }\end{array}$ \\
\hline $\begin{array}{c}\text { Early } \\
\text { Endosome }\end{array}$ & 4 & 0.919 & 0.965 & $\begin{array}{c}\mathrm{k} 1=1.107 \\
\mathrm{k} 2=0.84\end{array}$ & $\mathrm{M}=0.911$ \\
\hline & 4 & 0.471 & 0.816 & $\begin{array}{c}\mathrm{k} 1=1.222 \\
\mathrm{k} 2=0.546\end{array}$ & $\mathrm{M}=0.521$ \\
\cline { 2 - 6 } & 12 & 0.837 & 0.945 & $\begin{array}{c}\mathrm{k} 1=0.954 \\
\mathrm{k} 2=0.936\end{array}$ & $\mathrm{M}=0.72$ \\
\cline { 2 - 6 } & 24 & 0.665 & 0.892 & $\begin{array}{c}\mathrm{k} 1=1.165 \\
\mathrm{k} 2=0.682\end{array}$ & $\mathrm{M}=0.53$ \\
\hline \multirow{2}{*}{ Exsosome } & 12 & 0.794 & 0.923 & $\begin{array}{l}\mathrm{k} 1=1.201 \\
\mathrm{k} 2=0.713\end{array}$ & $\mathrm{M}=0.58$ \\
\hline
\end{tabular}




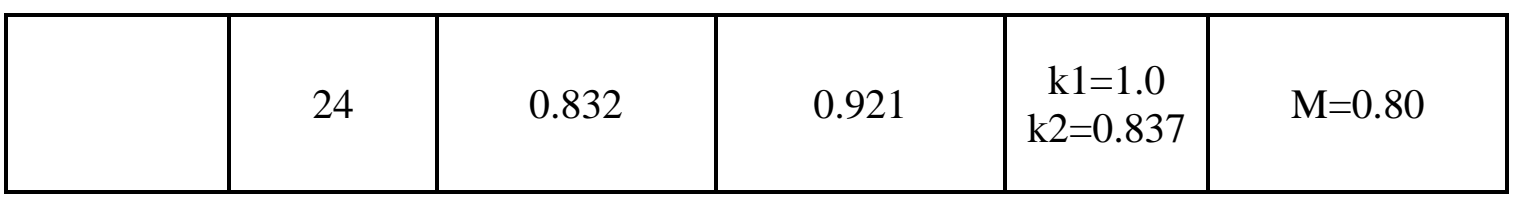

\subsection{Raman Spectroscopy}

Having confirmed the intracellular localisation of the nanoparticles at different exposure times using CLSM, Raman spectroscopy was employed to establish the spectroscopic signatures of the environment of the respective subcellular organelles. The software of the instrument (LabSpec6) allows the mapping of customized areas and when the total acquisition time for spectral maps and step size was considered, the total mapping time for each selected area of the cell was around 2-5 hrs. The use of selected areas instead of whole cell mapping decreases the total map acquisition time which provides stable conditions and increases sample integrity with higher resolution of the cellular compartments with small step sizes.

Polystyrene nanoparticles exhibit a characteristic Raman spectrum, as shown in Figure 3 II. They exhibit a strong Raman spectral signature, and the peaks around $620 \mathrm{~cm}^{-1}, 1001 \mathrm{~cm}^{-1}$, $1031 \mathrm{~cm}^{-1}, 1182 \mathrm{~cm}^{-1}, 1399 \mathrm{~cm}^{-1}, 1583 \mathrm{~cm}^{-1}$ and $1602 \mathrm{~cm}^{-1}$. Therefore, they can easily be identified within the cells ${ }^{15}$. A combination of multivariate analysis techniques can then be employed to extract the spectroscopic signatures of the subcellular environment of the cell.

After spectral maps were acquired, the data was analysed using KMCA and PCA in the Matlab platform. Before analysis, mild smoothing and normalisation were applied to the spectra to improve spectral quality (Section 2.5). The background, predominantly water in the immersion geometry ${ }^{41}$, was subtracted with Classical Least Squares (CLS) analysis. Following the pre-processing of data, KMCA was used to determine the localisation of nanoparticles within cells and PCA was applied to gain further information about the 
environment of the nanoparticles within the cell. The applicability of Raman spectroscopy with the aid of KMCA and PCA to differentiate different cellular regions as well as presence of particles within the cell after $24 \mathrm{hr}$ exposure has been shown and the results of the study were similar to Raman spectral maps of an A549 cell which were used as control in our study (Data not shown $)^{15,42}$. Once the nanoparticles were identified within the cells, in order to analyse the spectral signature of the subcellular environment further, the raw polystyrene spectrum was subtracted from the spectra of the K-means clusters associated with the polystyrene and polystyrene environment by using Non-negative least squares (NNLS) analysis. The underlying spectral signatures were further analysed using PCA, and the signatures for each time point are compared.

The Raman spectral map of an A549 cell acquired following $24 \mathrm{hr}$ particle exposure is shown in Figure 3. The white-light image of cells was obtained using the x100 immersion objective and the mapping area is indicated by the black line (Figure 3 IA). The mapping area, which includes the perinuclear region and neighbouring cytoplasm, was chosen according to the expected particle localisation area indicated by confocal microscopy to reduce the mapping time (Figure 1). The KMCA clearly differentiates a large perinuclear region (cluster 10, red in Figure $3 \mathrm{IB}$ ), as well as other regions of the neighbouring cytoplasm. A single K-means cluster containing clear signatures of polystyrene (PS) nanoparticles was clearly identified, as seen in Figure 3 II (cluster 6, pink in Figure 3 IB). For 24 hr particle exposure, most of the particles were observed in the perinuclear region which is consistent with the CLSM results (Figure 1 and Table 2). However, a few particles were observed in different K-means clusters of the neighbouring cytoplasm due to the continuity of particle uptake over $24 \mathrm{hrs}$. Some particles can be taken up later by the cell resulting in localisation in other subcellular vesicles such as lysosomes in the outer cytoplasmic area (cluster 1 and 7) as seen in Figure 1 and Table 2. When the mean spectra of K-means clusters were compared, characteristic 
polystyrene bands were clearly observed with high intensity in cluster 6 , compared to cluster 10 (Figure 3 II). Grey shading is used to identify polystyrene related bands. Notably, polystyrene bands with low intensity were also observed in the mean spectrum of the polystyrene environment.
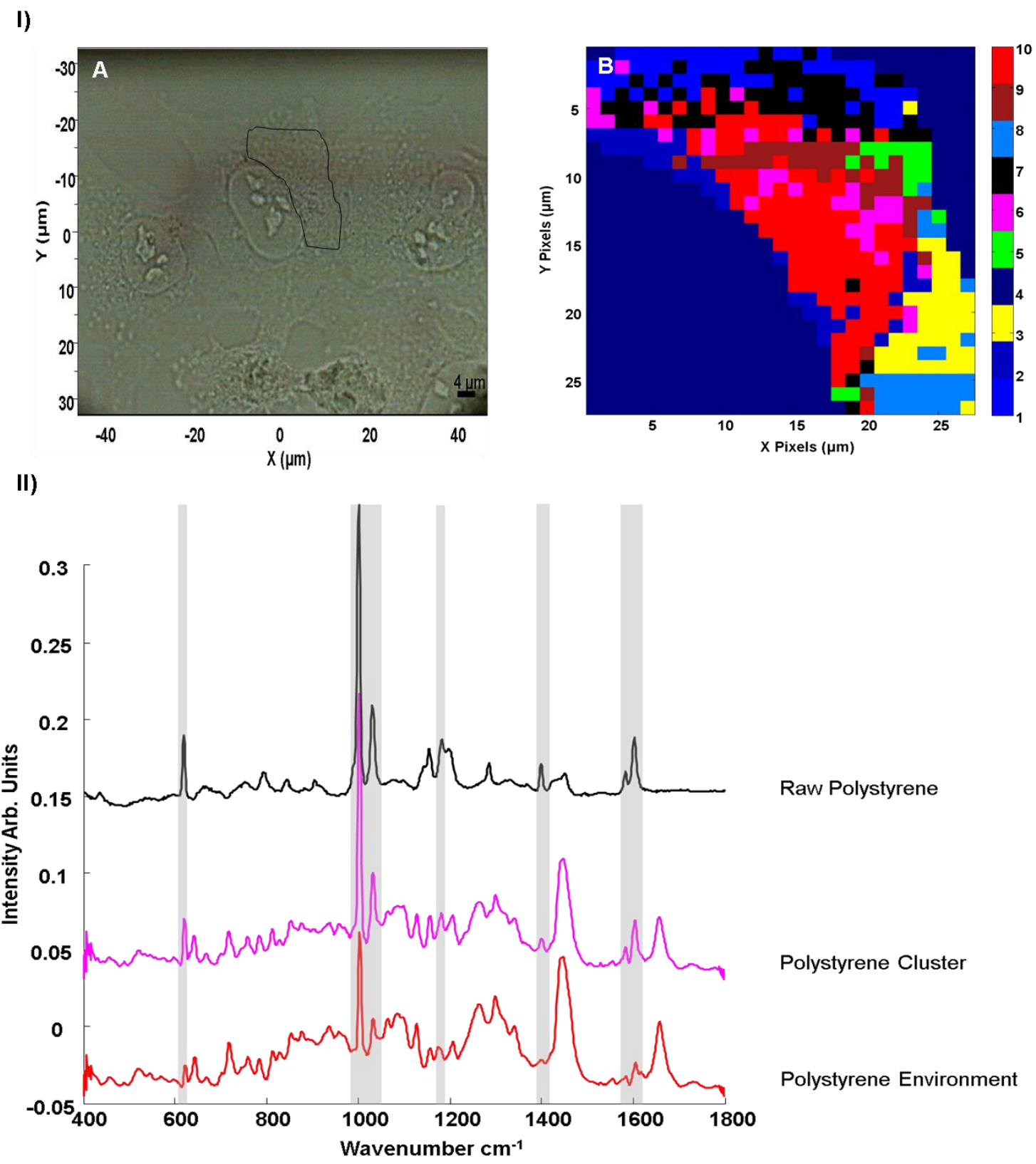

Figure 3. I(A) Typical white-light microscope image of an A549 cell after 24 hour exposure. The selected area defined by the black line indicates the area selected for Raman mapping (B), Example of K-means reconstructed image from a Raman map on the selected area of an 
A549 cell including the polystyrene environment, polystyrene cluster and cytoplasm. II) ; Raman spectrum of raw polystyrene nanoparticle and mean spectrum calculated for the different clusters obtained after K-means clustering which correspond to polystyrene cluster (Cluster 6, pink) and polystyrene environment (Cluster 10, red). Grey shading is used as a guide for polystyrene related peaks in the mean spectra. Spectra are offset for clarity.

PCA was carried out to further explore the differentiation between the polystyrene cluster (Kmeans Cluster 6, pink) and polystyrene subcellular environment (K-means cluster 10, red). Figure 4 IA shows the scatter plot of the PCA of spectra which correspond to the clusters. The KMCA cluster which is associated with polystyrene nanoparticles (pink) is clearly differentiated from that of the nanoparticle environment (red), according to PC1, the loading of which is dominated by negative features corresponding to the spectrum of raw polystyrene, indicated by the grey shading in Figure 4 IIA. On the other hand, the positive loading of PC1 provides information about the biochemical composition of the polystyrene environment and many peaks can be clearly observed which can be attributed to specific biochemical constituents: features at $718-733 \mathrm{~cm}^{-1}$ are related to lipids and nucleic acids, $1231-1284 \mathrm{~cm}^{-1}$ to nucleic acids, lipids and proteins and several bands between $1400-1600 \mathrm{~cm}^{-1}$ are related to proteins and lipids and the Amide I of proteins features strongly at $1600 \mathrm{~cm}^{-1}$ (Figure 4 IIA $)^{43-45}$.

It is noted that some spectra identified by KMCA as neighbouring environment can be seen in the negative side of scatter plot, indicating polystyrene contributions to the spectra which is similar to the observations of Dorney et $a .^{15}$. KMCA is a hard clustering algorithm which clusters spectra of similar character but does not account for mixed contributions. PCA clearly indicates contributions of PS in these spectra. In order to show the contribution of the raw polystyrene spectrum in the environment cluster, the raw polystyrene spectrum was 
subtracted from the spectra of the environmental cluster by using CLS (Supplementary Information S2.1). After polystyrene subtraction from the spectra of the environment cluster, the explained variance was increased from $42 \%$ to $62 \%$ and the spectra of the two clusters were better separated and clustered.
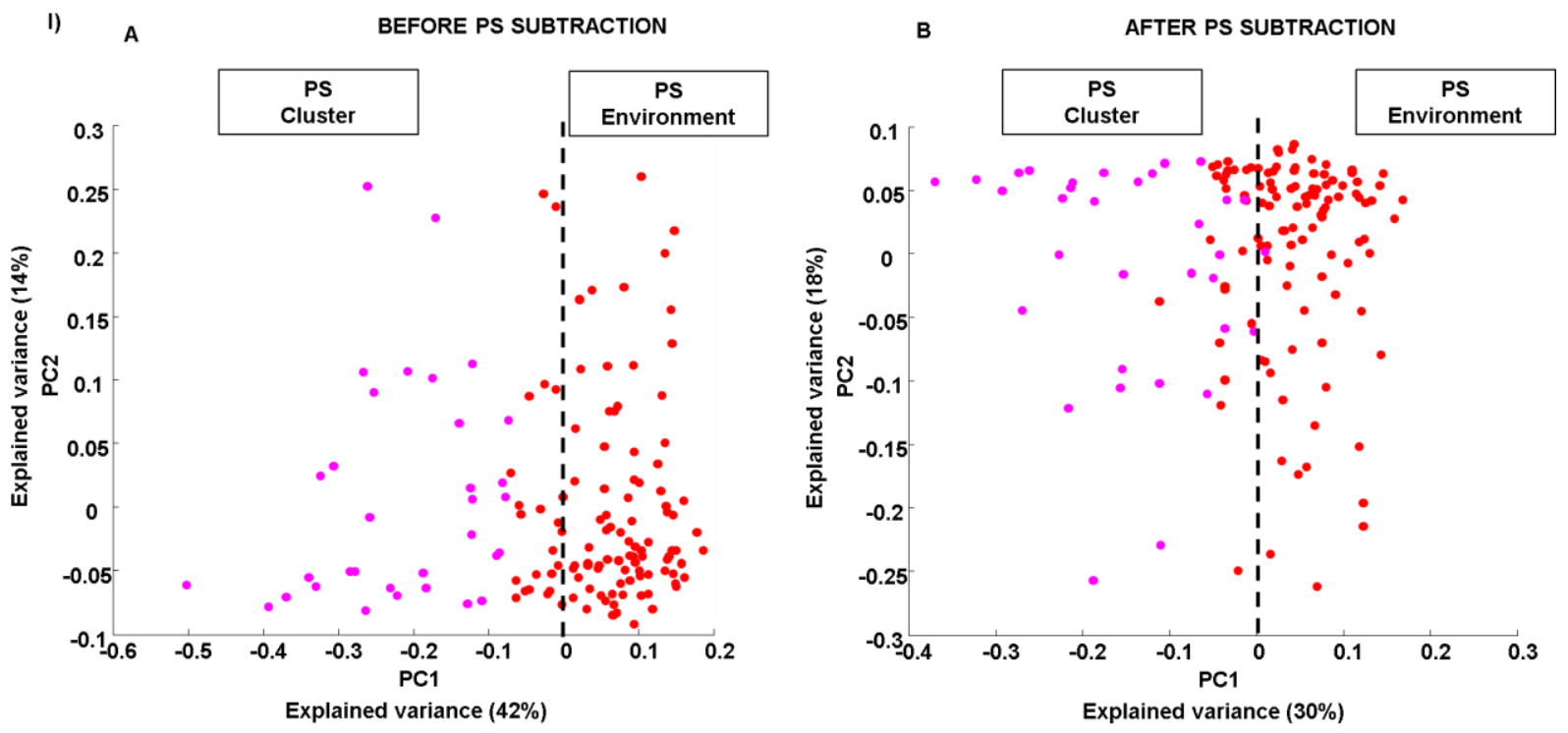

II)

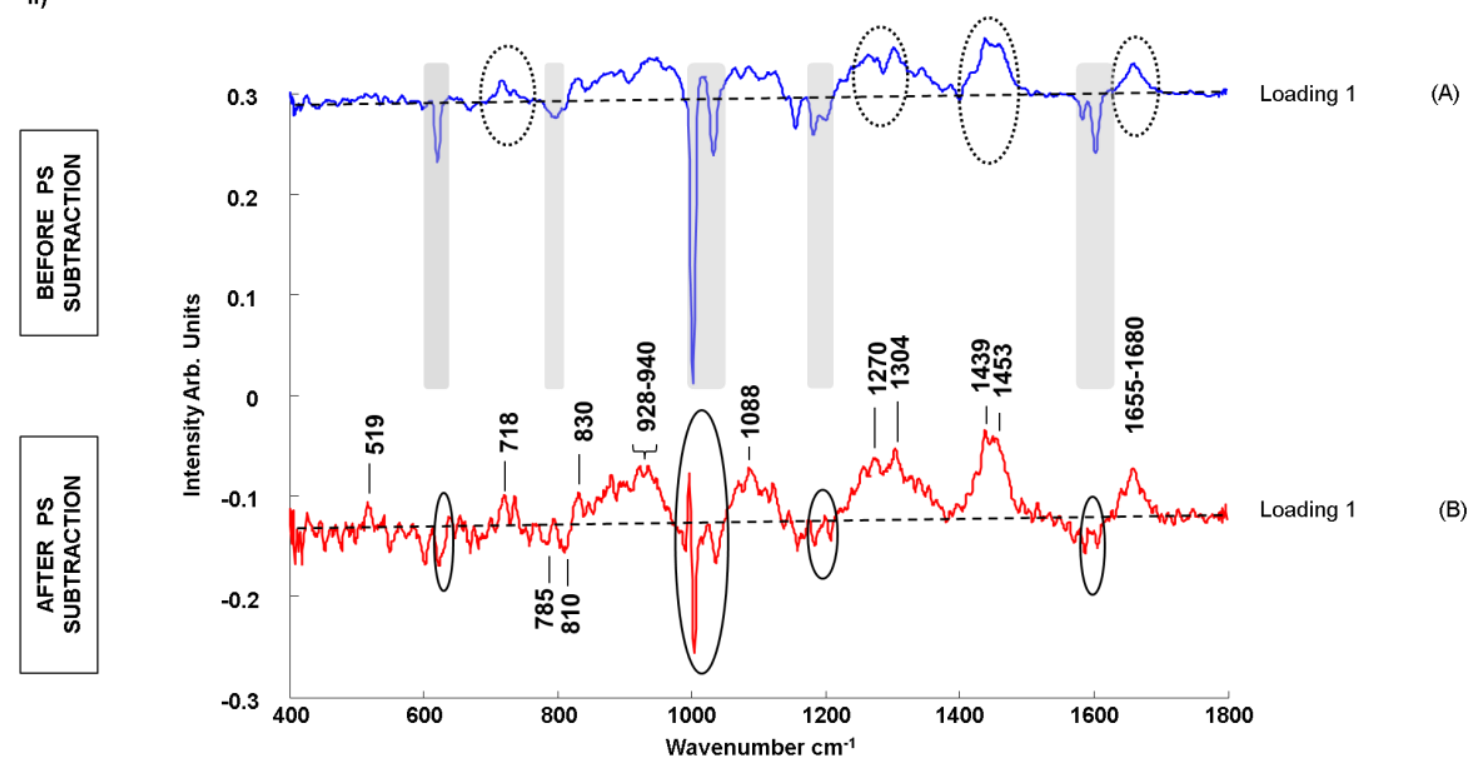

Figure 4. I(A), Scatter plot of the PCA of spectra corresponding to the KMCA clusters of polystyrene (pink) and polystyrene environment (red) for 24 hour particle exposure before PS subtraction. (B), Scatter plot of the PCA of spectra corresponding to polystyrene nanoparticles and polystyrene environment after raw polystyrene spectrum subtracted for 24 
hour particle exposure. II) ; Loading of PC1 before (A) and after (B) polystyrene subtraction. In the loading of $\mathrm{PC} 1$ before PS subtraction, characteristic peaks of polystyrene are highlighted with grey and bands which can be attributed to the presence of nucleic acids, proteins and lipids were indicated with black circles (A). In the loading of PC1 of polystyrene cluster and polystyrene environment after PS subtraction, possible polystyrene residues are indicated with black circles and band assignments are made according to Table 3 (B). Spectra are offset for clarity. The dotted line represents the ' 0 ' line for each loading.

In order to further elucidate the spectroscopic signatures of the neighbouring environment and the area which includes polystyrene nanoparticles, the raw spectrum of polystyrene was subtracted from the spectra of each of the respective K-means clusters. Figure 4 IB shows the scatter plot of the PCA of spectra after subtraction of the raw polystyrene spectrum from both the polystyrene and neighbouring environment clusters. After subtraction, the explained variance in the scatter plot of the PCA was reduced to $30 \%$ from $42 \%$, which indicates that the spectrum of the underlying biological environment of the nanoparticle cluster itself is similar to that of the neighbouring environment cluster. Nevertheless, the two clusters are differentiated negatively and positively with respect to PC1, although again there is some overlap of the environment cluster on the negative side. In order to compare spectral differences between spectra which are loaded positively and negatively with respect to PC1, mean spectra related to $\mathrm{PC} 1 \geq 0$ and $\mathrm{PC} 1<0$ are calculated. Figure 5 presents the mean of all points which score positively (PS neighbouring environment) or negatively (underlying PS biological environment) with respect to PC1 in Figure 4 IB. Residual PS is clearly evidenced in both spectra by the feature at $\sim 1004 \mathrm{~cm}^{-1}$. Moreover, polystyrene bands at $620 \mathrm{~cm}^{-1}$ and $1600 \mathrm{~cm}^{-1}$ are observed in the mean spectra of the underlying PS biological environment. The specific differences between the spectra of the underlying PS biological environment and the 
neighbouring environment are better visualised in the PC loading after raw polystyrene subtraction, shown in Figure 4 IIB.

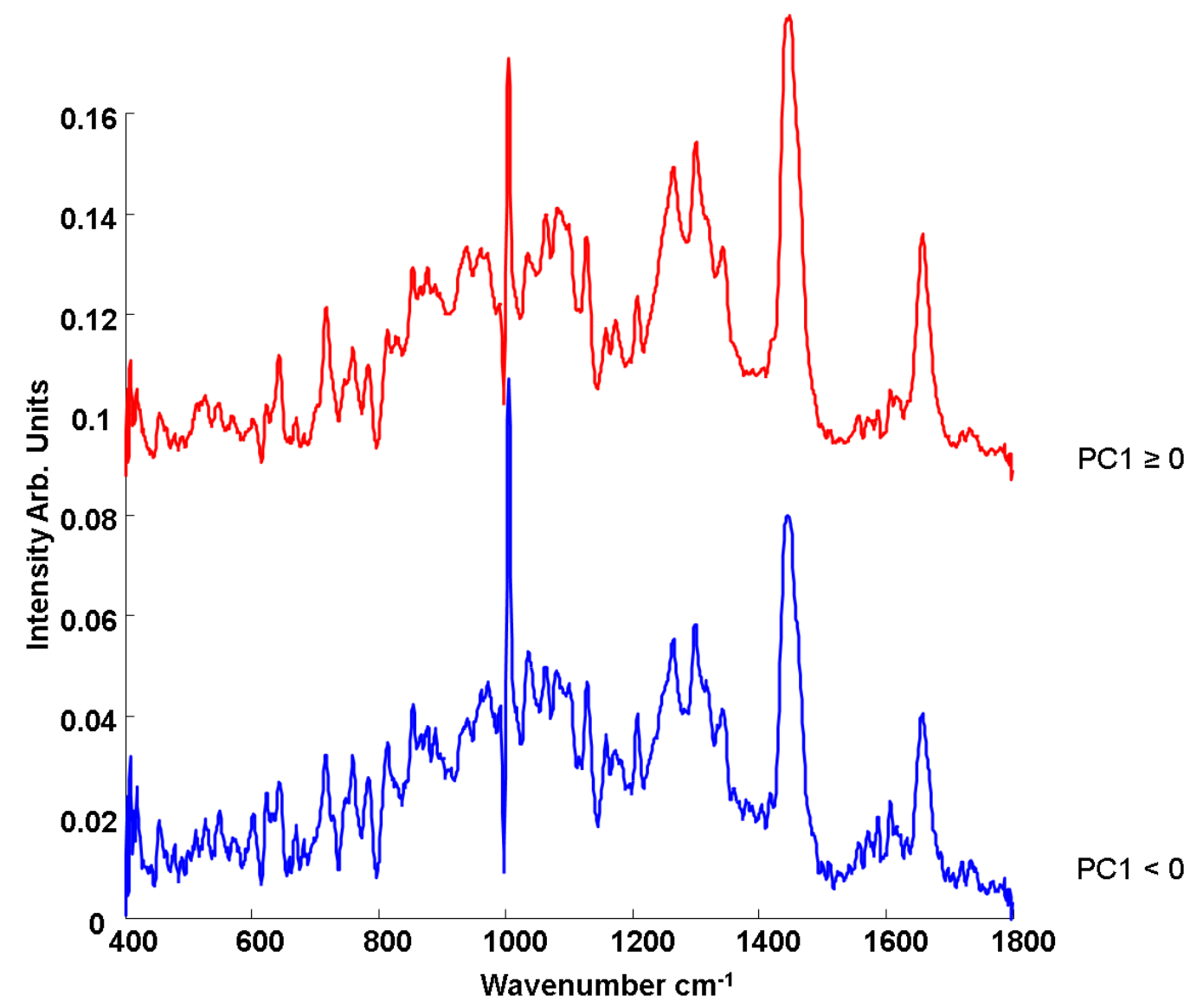

Figure 5. Mean spectra of PS environment cluster (Loading of PC1 $\geq 0$ ) and PS cluster (Loading of PC1<0) after PS subtraction for 24 hour exposure. Spectra are offset for clarity.

The bands observed in the loading of PC1 can be attributed to differences in the biological environment underlying the polystyrene cluster and the neighbouring environment cluster. Although subtraction of the raw polystyrene spectrum has significantly reduced the negative differentiating features of the raw polystyrene spectrum, some residual polystyrene bands can be observed after subtraction due to the high variability of the intensity of bands in the large Raman map data sets. Therefore, in Figure 4 IIB, possible residues of polystyrene bands at $620 \mathrm{~cm}^{-1}, 1001 \mathrm{~cm}^{-1}, 1182 \mathrm{~cm}^{-1}$ and $1602 \mathrm{~cm}^{-1}$ are indicated with black circles and they are excluded from band assignments. 
When the bands in the loading of PC1 after raw polystyrene subtraction are analysed in further detail, it can be seen that the positive contributions which relate to the neighbouring PS environment are dominated by bands at $519 \mathrm{~cm}^{-1}, 718 \mathrm{~cm}^{-1}$, which are indicative of the presence of phosphatidylinositol and membrane lipids, respectively. Moreover, the bands at around $1088 \mathrm{~cm}^{-1}, 1270 \mathrm{~cm}^{-1}, 1304 \mathrm{~cm}^{-1}$ and $1439 \mathrm{~cm}^{-1}$, are also associated with lipids, while protein related bands are observed at $\sim 830 \mathrm{~cm}^{-1}, 928-940 \mathrm{~cm}^{-1}$ and $1453 \mathrm{~cm}^{-1}$. The band around $1660 \mathrm{~cm}^{-1}$ can be attributed to the Amide I (C-N stretch) of proteins, but also in the same region, bands in the range between $1655-1680 \mathrm{~cm}^{-1}$ can be attributed to $\mathrm{C}=\mathrm{O}$ stretch of lipids (Figure $4 \mathrm{IIB})^{43-45}$. On the other hand, the negative loading of PC1 is dominated by polystyrene features with two bands which can be attributed to the presence of RNA, necessary for protein synthesis, at $785 \mathrm{~cm}^{-1}$ and $810 \mathrm{~cm}^{-1}$. When the results are compared with the CLSM results, it is clear to say that particles localise in a perinuclear area which is rich in lipid and protein content. The endoplasmic reticulum is known to be the largest organelle within cells with varying size depending on cell type (generally more than $10 \%$ of cell composition) and the spatially organized structure of the endoplasmic reticulum is mainly located in the perinuclear region ${ }^{46}$, and thus the underlying spectral signature can be associated with that of the endoplasmic reticulum (Figure 4 IIB and Table 3).

Table 3. Band assignments related to polystyrene cluster and polystyrene environment after 24 hour particle exposure ${ }^{43-45}$.

\begin{tabular}{|c|c|c|}
\hline $\begin{array}{c}\text { Band } \\
\text { Assignment } \\
\left(\mathrm{cm}^{-1}\right)\end{array}$ & $\begin{array}{c}\text { Polystyrene } \\
\text { Cluster }\end{array}$ & $\begin{array}{c}\text { Polystyrene } \\
\text { Environment }\end{array}$ \\
\hline 519 & - & Phosphatidylinositol \\
\hline 718 & - & Membrane lipids \\
\hline
\end{tabular}




\begin{tabular}{|c|c|c|}
\hline 785 & RNA & - \\
\hline 810 & Nucleic acids & - \\
\hline 830 & - & Proteins \\
\hline $928-940$ & - & Proteins \\
\hline 1088 & - & Lipids \\
\hline 1270 & - & Lroteins\&Lipids \\
\hline 1304 & - & Lipids \\
\hline 1439 & - & Proteins \\
\hline 1453 & - & Proteins\&Lipids \\
\hline $1655-1680$ & & \\
\hline
\end{tabular}

After polystyrene particles are taken up by cell, they are carried to lysosomes by endosomes and, after $12 \mathrm{hrs,} \mathrm{they} \mathrm{mainly} \mathrm{localize} \mathrm{in} \mathrm{lysosomes,} \mathrm{as} \mathrm{seen} \mathrm{in} \mathrm{Table} \mathrm{2,} \mathrm{and} \mathrm{Figure} \mathrm{1.} \mathrm{For} \mathrm{this}$ reason, the second exposure time to examine the particle localisation and neighbouring environment within the cell using Raman spectroscopy was chosen as 12 hrs and Raman maps were acquired as before from A549 cells (Figure 6). As seen in the CLSM images (Figure 1), the distribution of lysosomes within the cell is much wider than the endoplasmic reticulum. Therefore, the customised Raman mapping area was chosen to be larger for $12 \mathrm{hr}$ exposure time compared to the $24 \mathrm{hr}$ exposure (Figure 6 IA). The selected area for mapping shows K-means clustering due to the influence of different thickness of the nucleus, cytoplasm and the edge of cell. When the mapped area includes the edge and outside of the cell, the use of higher number of clusters is needed because of the variety in composition ${ }^{15}$. In the $12 \mathrm{hr}$ data set, the customised area was composed of the nuclear area and inner cytoplasm (Figure 6 IA). For this reason, 6 different clusters of K-means were used to determine the polystyrene localisation. As seen in Figure 6 IB, a number of distinct clusters were identified and polystyrene nanoparticles are clearly identifiable in the mean spectra of cluster 5 (brown), compared to the neighbouring environment of cluster 3 (green) (Figure 6 II.). 

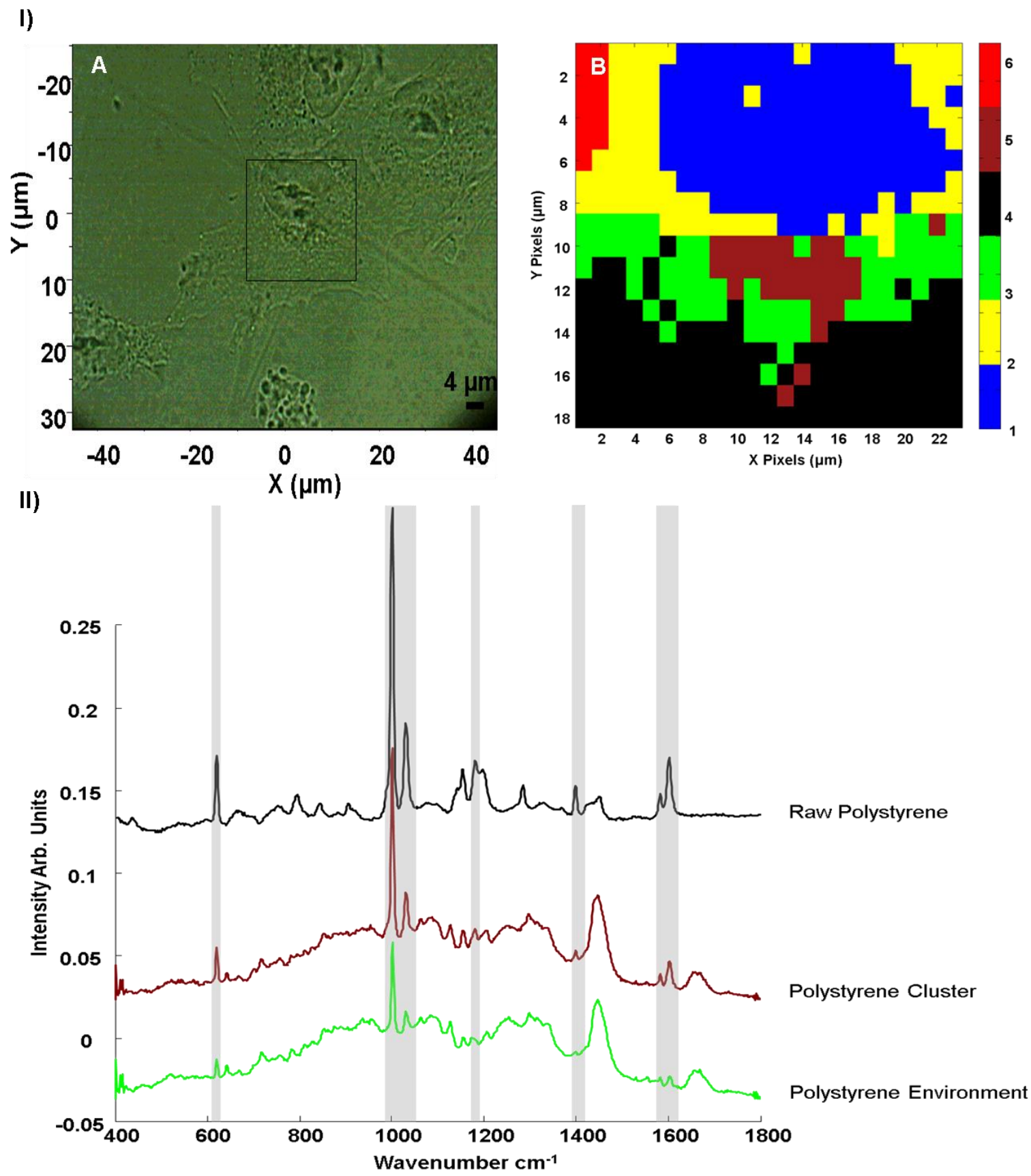

Figure 6. I(A) Typical white-light microscope image of an A549 cell after 12 hour exposure. The selected area defined by the black line indicates the area selected for Raman mapping (B), Example of K-means reconstructed image from a Raman map on the selected area of an A549 cell including the polystyrene environment, polystyrene cluster and cytoplasm and nucleus. II) ; Raman spectrum of raw polystyrene nanoparticle and mean spectrum calculated for the different clusters obtained after K-means clustering which correspond to polystyrene cluster (Cluster 5, brown) and polystyrene environment (Cluster 3, green). Grey shading is 
used as a guide for polystyrene related peaks in the mean spectra. Spectra are offset for clarity.

Figure 7 IA shows the PCA scatter plot of the spectra associated by KMCA with the polystyrene nanoparticles (Cluster 5, brown) and their neighbouring environment (Cluster 3, green) for $12 \mathrm{hr}$ exposure, colour coded as per Figure 6 IB. The clusters are well differentiated according to the loading of PC1 (44\% Explained Variance) and the loading is dominated by strong negative peaks of polystyrene at $620 \mathrm{~cm}^{-1}, 800 \mathrm{~cm}^{-1}, 1001 \mathrm{~cm}^{-1}, 1031$ $\mathrm{cm}^{-1}, 1182 \mathrm{~cm}^{-1}, 1583 \mathrm{~cm}^{-1}$ and $1602 \mathrm{~cm}^{-1}$, as shown in Figure 7 IIA. As was observed for the $24 \mathrm{hr}$ exposure data set, some spectra of the polystyrene neighbouring environment KMCA cluster are identified by PCA as containing strong polystyrene contributions, in addition to cellular Raman bands at $1280 \mathrm{~cm}^{-1}$ and $1439 \mathrm{~cm}^{-1}$, which are related to the Amide III of proteins and lipids, respectively ${ }^{43-45}$. When the polystyrene spectrum is subtracted from the spectra of the polystyrene neighbouring environment cluster, the explained variance is increased to $60 \%$ and the spectra related to the polystyrene environment cluster became significantly differentiated from the polystyrene cluster in the scatter plot (Supplementary Information Figure S2.2).

In order to extract information about the underlying biochemical composition of the polystyrene cluster which possibly derives from the lysosomal biochemical content, the raw polystyrene spectrum was subtracted from both the spectra of the polystyrene cluster and the polystyrene neighbouring environment cluster of the $12 \mathrm{hr}$ exposure data set. The explained variance of the PCA scatter plot is reduced to $26 \%$ from $44 \%$, as seen in Figure 7 IB.

Lysosomes can typically vary from 0.1 to $1.2 \mu \mathrm{m}$ in $\operatorname{size}^{47}$. Whereas the Raman spot size is significantly smaller that the ER, it is comparable to the size of the lysosomes and thus a 
more significant contrast may be expected between the underlying biological content of the PS cluster, which should be characteristic of lysosomes and their neighbouring environment, the cytoplasm.
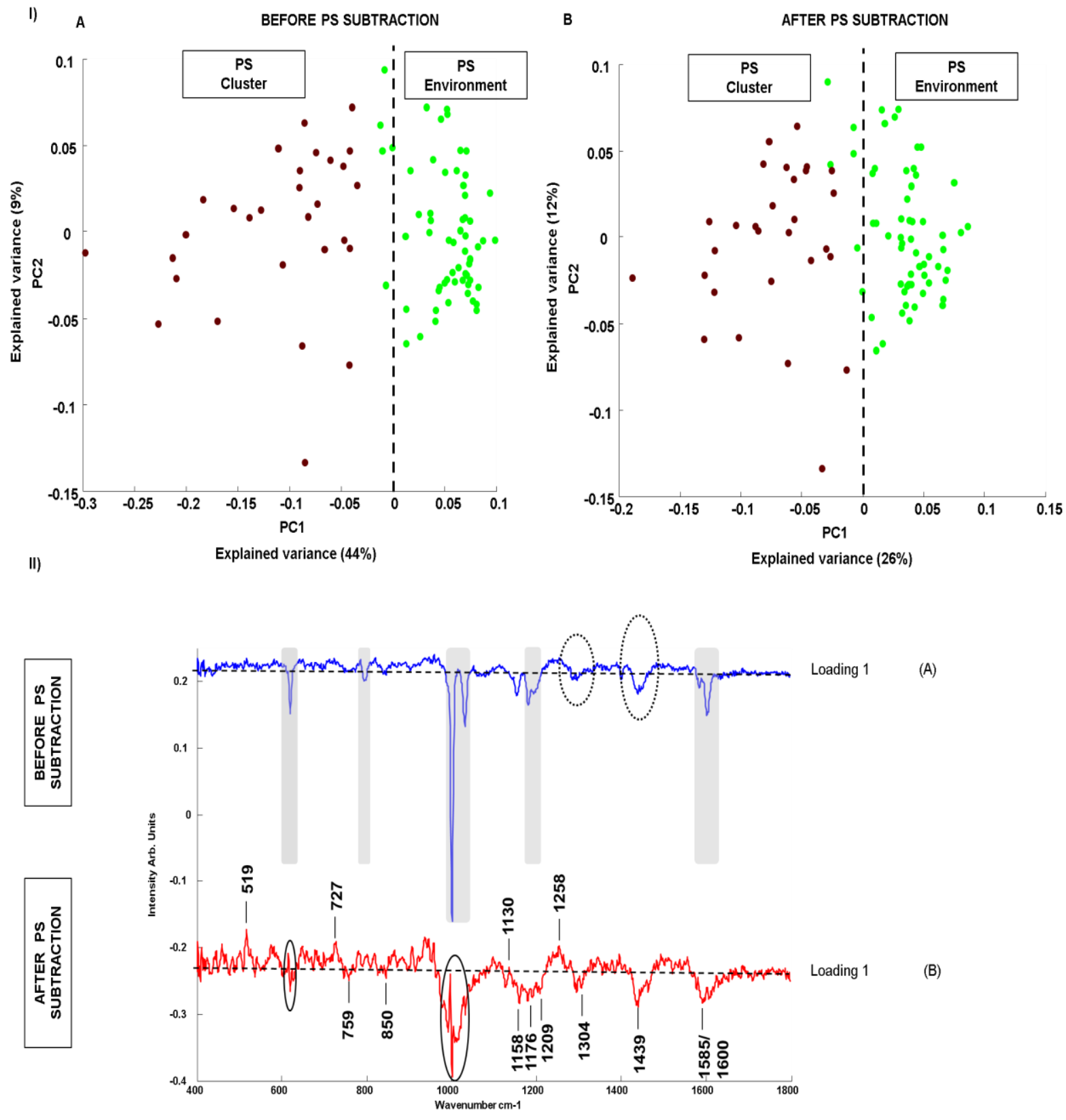

Figure 7. I(A), Scatter plot of the PCA of spectra corresponding to the polystyrene cluster (brown) and polystyrene environment (green) for 12 hour particle exposure before PS subtraction. (B), Scatter plot of the PCA of spectra corresponding to the polystyrene cluster 
and polystyrene environment for 12 hour particle exposure, after subtraction of the raw polystyrene spectrum. II) ; Loading of PC1 before (A) and after (B) polystyrene subtraction. In the loading of PC 1 before subtraction, characteristic peaks of polystyrene are highlighted with grey and bands which can be attributed to presence of proteins and lipids were indicated with black circles (A). In the loading of PC1 after PS subtraction, possible polystyrene residues are indicated with black circles and band assignments are made according to Table 4 (B). Spectra are offset for clarity. The dotted line represents the ' 0 ' line for each loading.

Similar to $24 \mathrm{hr}$ exposure data set, although they are well differentiated by PC1, some overspill of the neighbouring environment cluster into the polystyrene cluster is observed, both before and after subtraction of the PS spectrum from that of both clusters. After subtraction, when mean spectra are calculated for the positive and negative sides of PC1, similar spectra are obtained, as shown in Figure 8. Moreover, the mean spectrum of the cytoplasm (Cluster 4) is also shown to highlight the similarities of the spectra of the biological environment underlying the polystyrene and the neighbouring environment after $12 \mathrm{hr}$ exposure. Residual PS features are apparent in both spectra, to a lesser extent than for the $24 \mathrm{hr}$ exposure, and some differentiating bands at 1607 and $1617 \mathrm{~cm}^{-1}$ which are related to the $\mathrm{C}=\mathrm{C}$ bond in Tyr, Trp and Phe and a broad band in the range between $1231-1284 \mathrm{~cm}^{-1}$ which can be attributed the Amide III (both $\alpha$-helix and $\beta$-sheet) region of proteins as well as lipids are evident. On the other hand, the most significant differentiating bands for the cytoplasm are observed at 508 and $1254 \mathrm{~cm}^{-1}$ which relates to the disulfide bond (S-S stretch) and Amide III ( $ß$-sheet) of proteins. These differentiating bands are best visualised in the loading of PC1 (Figure 7 IIB). 


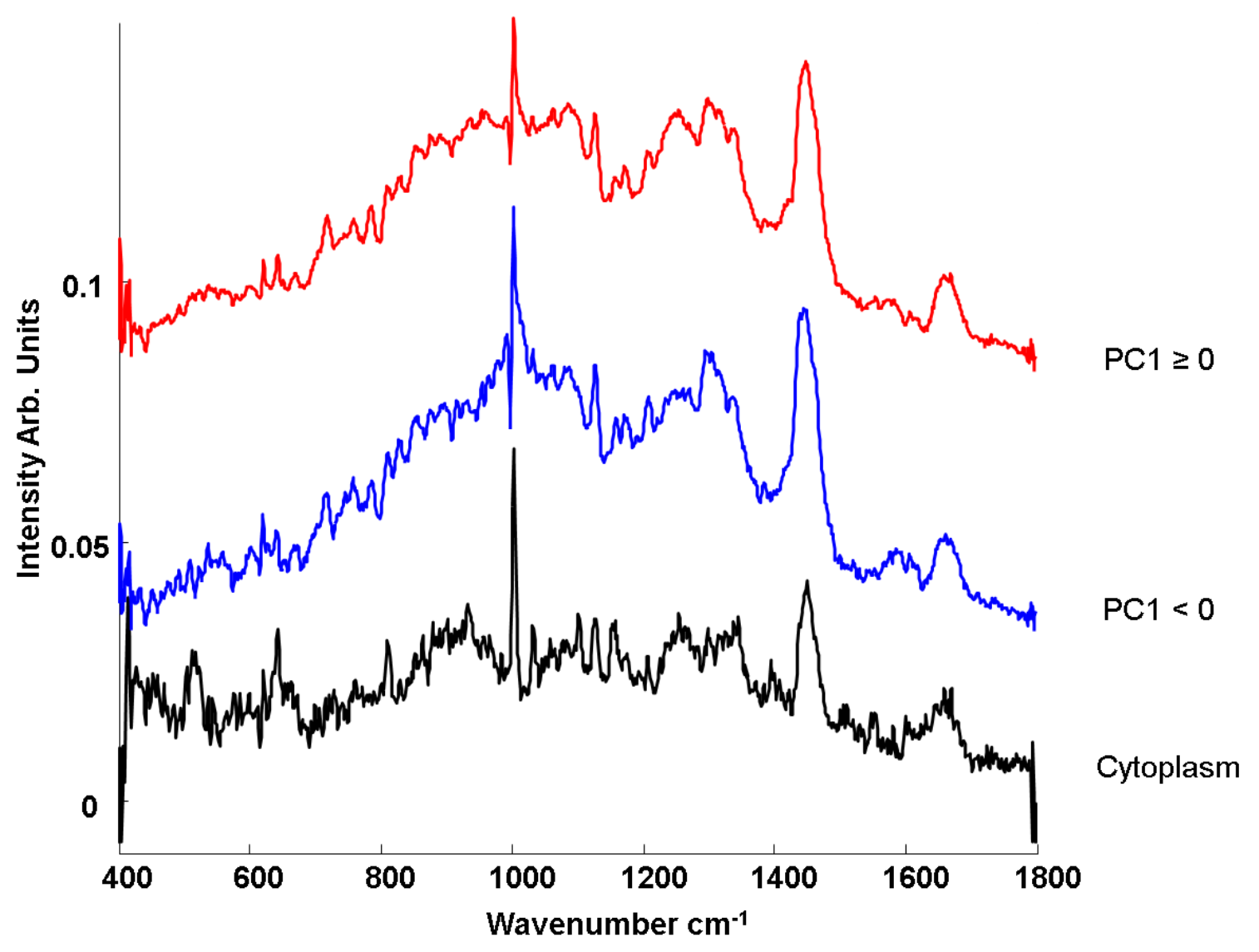

Figure 8. Mean spectra of PS environment cluster (Loading of PC1 $\geq 0$, red), PS cluster (Loading of PC $1<0$, blue) after PS subtraction for 12 hour exposure and spectrum of cytoplasm (black). Spectra are offset for clarity.

As seen in Figure 7 IIB, some polystyrene residues, indicated by the black circles, at $620 \mathrm{~cm}^{-1}$ and $1001 \mathrm{~cm}^{-1}$, remain after subtraction and these are excluded from the band assignments (Table 4). Many peaks related to lipids can be seen clearly at $519 \mathrm{~cm}^{-1}$ (phosphatidylinositol) and $1130 \mathrm{~cm}^{-1}$ (structural changes of phospholipids) in the positive loading of PC1, associated with the spectra of the neighbouring environment ${ }^{44-46}$. Moreover, bands at $727 \mathrm{~cm}^{-}$ 1 and $1258 \mathrm{~cm}^{-1}$ (Amide III), which can be attributed to presence of proteins in the neighbouring environment cluster, can be seen in the positive loading of PC1. In contrast to 
the case for $24 \mathrm{hr}$ exposure, the dominant, negative features of the loading of PC1, associated with the underlying biological content of the PS cluster, feature negative loadings of lipid bands at $759 \mathrm{~cm}^{-1}$ (phosphatidylethanolamine), $1304 \mathrm{~cm}^{-1}$ and $1439 \mathrm{~cm}^{-1} 36$. Even though they are not as dominant as in the $24 \mathrm{hr}$ exposure data, some protein bands can be identified at 850 $\mathrm{cm}^{-1}, 1158 \mathrm{~cm}^{-1}, 1176 \mathrm{~cm}^{-1}, 1209 \mathrm{~cm}^{-1}, 1600 \mathrm{~cm}^{-1}$ (Amide I) in the negative loading of PC1. For the $12 \mathrm{hr}$ exposure data set, the band at $1585 \mathrm{~cm}^{-1}$ can be attributed to Phe, which has associated bands across the rest of the spectrum at $1209 \mathrm{~cm}^{-1}$ and $1607 \mathrm{~cm}^{-1}$. Also, the wider band around $1010 \mathrm{~cm}^{-1}$ compared to the $24 \mathrm{hr}$ exposure data set can be explained by symmetric ring breathing of Phe. Band assignments can be seen in detail in Table 4.

Table 4. Band assignments related to the underlying biological environment of the polystyrene cluster and the neighbouring polystyrene environment after 12 hour particle exposure $^{43-45}$.

\begin{tabular}{|c|c|c|}
\hline $\begin{array}{c}\text { Band } \\
\text { Assignment } \\
\left(\mathrm{cm}^{-1}\right)\end{array}$ & $\begin{array}{l}\text { Polystyrene } \\
\text { Cluster }\end{array}$ & $\begin{array}{l}\text { Polystyrene } \\
\text { Environment }\end{array}$ \\
\hline 519 & - & Phosphatidylinositol \\
\hline 727 & - & Protein \\
\hline 759 & phosphatidylethanolamine & - \\
\hline 850 & Protein & - \\
\hline 1004 & Phe & - \\
\hline 1130 & - & Lipids \\
\hline 1158 & Protein & - \\
\hline 1176 & Protein & - \\
\hline 1209 & Protein & - \\
\hline 1258 & - & Protein \\
\hline 1304 & Lipids & - \\
\hline 1439 & Lipids & - \\
\hline
\end{tabular}




\section{5-1600}

Proteins

The band assignments of Figure 7 IIB can be used to elucidate the biochemical content of the underlying PS biological environment and the neighbouring environment, which are related to lysosomes and cytoplasm, respectively. The negative bands in the loading of PC1, associated with the polystyrene cluster, indicate the presence of lipids and proteins, as shown in table 4. There are some negatively loaded peaks in PC1, associated with the polystyrene cluster, but those that are identifiable are largely associated with high intensity Raman bands of lipids. Notably, there is no indication of the presence of nucleic acids, which were prominent in the environment of the $24 \mathrm{hr}$ exposure (Table 3). In the $12 \mathrm{hr}$ exposure data set, the dominance of the negative features of the underlying PS biochemical environment in the loading of PC1 after raw polystyrene subtraction can be attributed to localisation within the higher density lysosomes in cytoplasm, which has quite low Raman signal.

For $4 \mathrm{hr}$ exposure, particles mainly localize in early endosomes, as seen by CLSM with early endosome staining (Figure 2) and it has previously been shown that the nanoparticles are largely present in vesicles individually rather than as aggregates, as in the case of lysosomes $^{13}$. As a result, the associated Raman signals are significantly lower than at longer exposure times. Moreover, the wide distribution of early endosomes in the cytoplasm and low inherent signal of the relatively thin outer cytoplasm makes the observation of nanoparticles for $4 \mathrm{hr}$ exposure time challenging. Figure 9 shows the results of Raman spectral mapping of an A549 cell after $4 \mathrm{hr}$ exposure. The white-light image of the cells was obtained using a x100 immersion objective and the customised mapping area is indicated with the black line (Figure 9 IA). The mapping was performed over a larger area and 10 different K-means clusters were used in the analysis. Clusters containing signatures of PS nanoparticles were identifiable although the suggested polystyrene related clusters (Cluster 8) cover most of the 
area of the cytoplasm, surrounded by Cluster 4, as seen in Figure 9 IB. The presence of polystyrene nanoparticles can be still recognized by the slightly higher intensity of the characteristic bands of polystyrene in some clusters, as shown in Figure 9 II. The characteristic polystyrene band at $1004 \mathrm{~cm}^{-1}$ overlaps with the band from phenylalanine, and therefore the polystyrene band at $1602 \mathrm{~cm}^{-1}$, which is marked with '*' in Figure 9 II, can be used as a clearer indicator band for the presence of polystyrene.
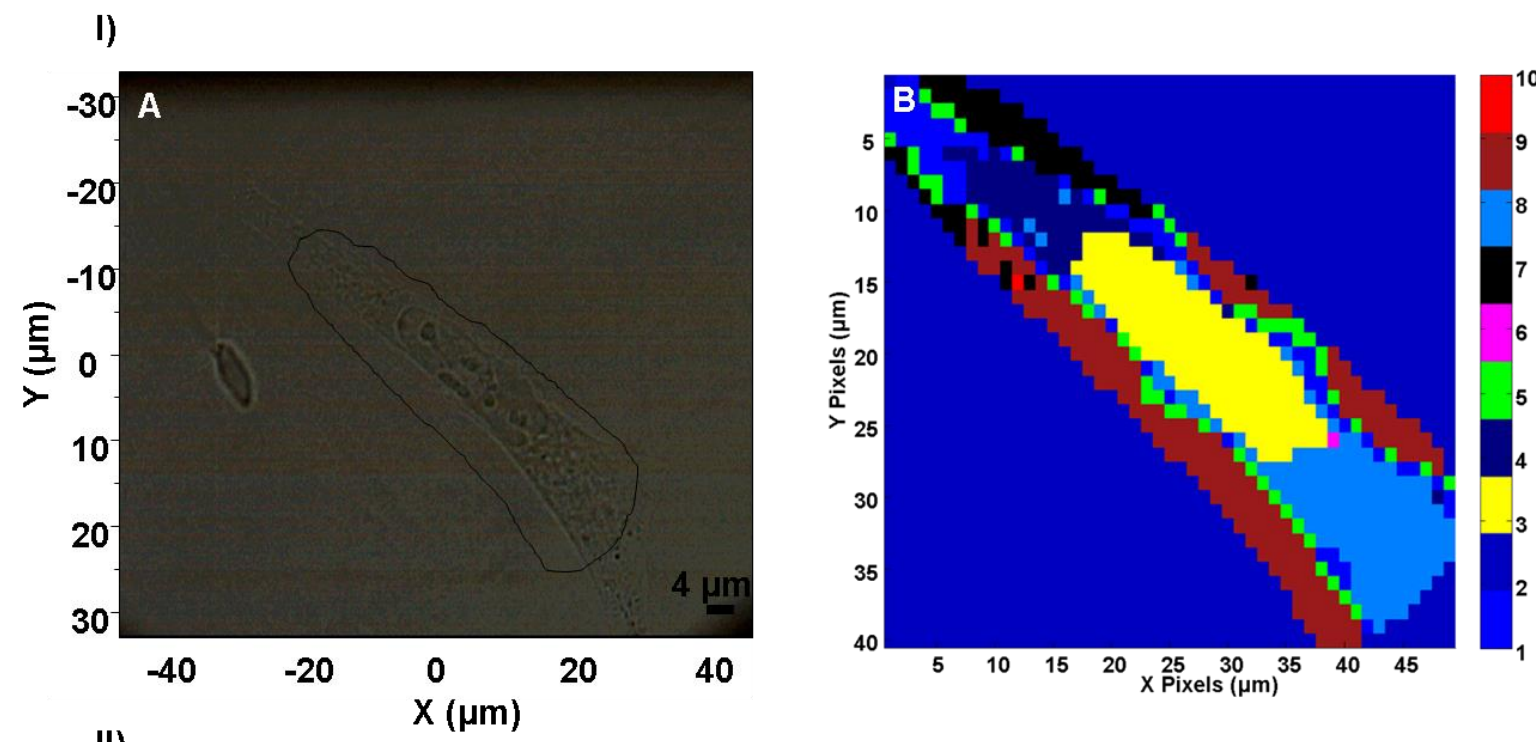

II)

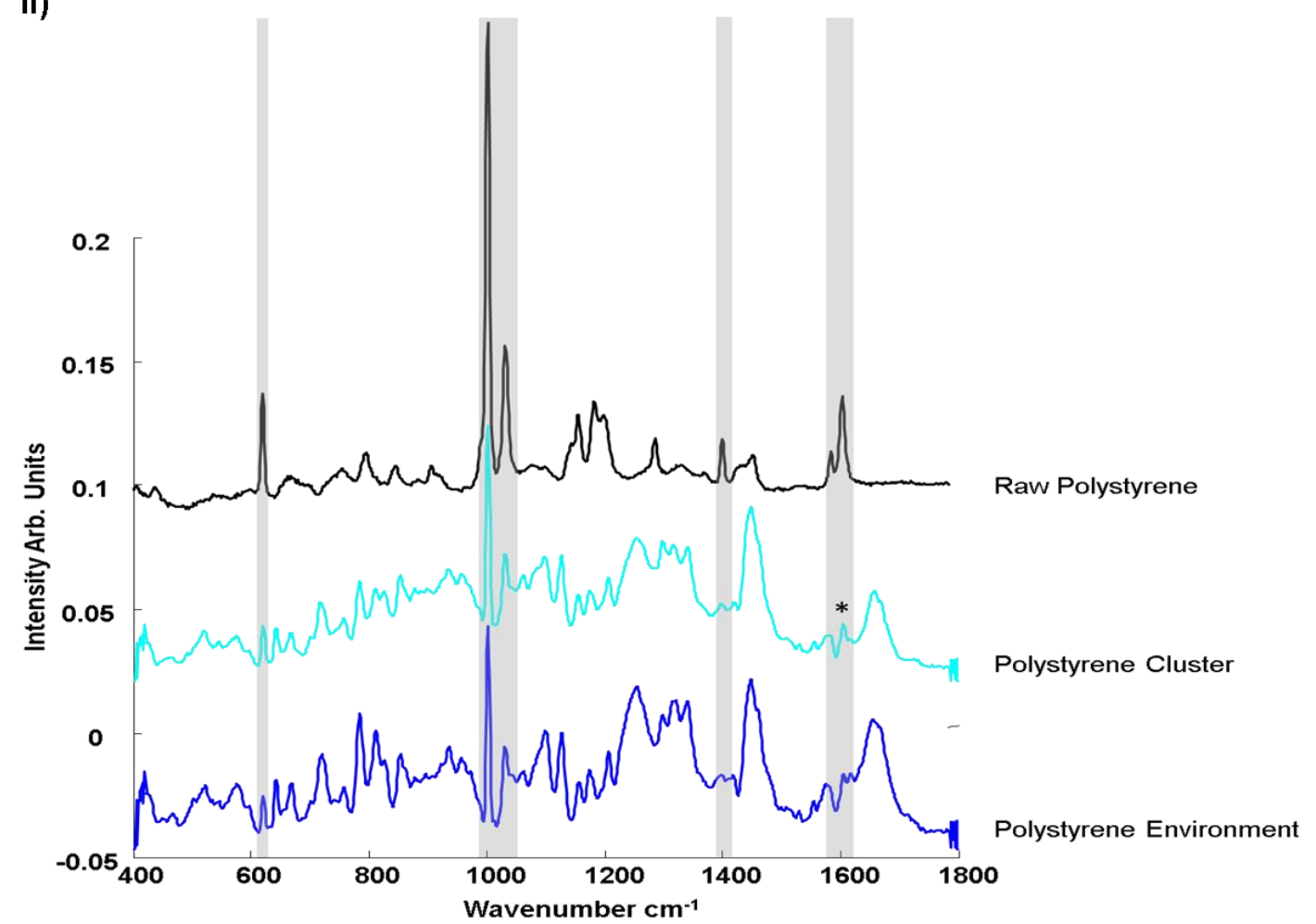


Figure 9. I(A) Typical white-light microscope image of an A549 cell after 4 hour exposure. The selected area defined by the black line indicates the area selected for Raman mapping (B), Example of K-means reconstructed image from a Raman map on the selected area of an A549 cell including the polystyrene environment, polystyrene cluster and cytoplasm, nucleus and substrate. II) ; Raman spectrum of raw polystyrene nanoparticle and mean spectrum calculated for the different clusters obtained after K-means clustering which correspond to polystyrene cluster (Cluster 8, light blue) and polystyrene environment (Cluster 4, dark blue). Grey shading is used as a guide for polystyrene related peaks in the mean spectra. '*' used as an indicator of polystyrene features in the polystyrene cluster. Spectra are offset for clarity.

Figure 10A shows the scatter plot of the PCA of spectra which correspond to clusters identified as having spectral signatures of polystyrene nanoparticles and their neighbouring environment. The KMCA cluster which is associated with polystyrene nanoparticles (Cluster 8, light blue) is largely differentiated from that of the neighbouring environment (Cluster 4 , dark blue), according to PC1. As can be seen from the loading of PC1 in Figure 10B, however, no strong features associated with polystyrene nanoparticles are observable. Positive features of the loading of PC1 can be seen at $785 \mathrm{~cm}^{-1}$ (U, T, C bases of RNA) and $810 \mathrm{~cm}^{-1}$ (Phosphodiester $\mathrm{Z}$ marker), indicating the presence of nucleic acids. On the other hand, a $1004 \mathrm{~cm}^{-1}$ peak relates to protein, a $1280 \mathrm{~cm}^{-1}$ peak relates to the Amide III band of proteins and a strong lipid band at $1439 \mathrm{~cm}^{-1}$ are observed as negative loadings of PC1. As seen in Figure $9 \mathrm{IB}$, the neighbouring environment cluster (Cluster 4) includes both the outer cytoplasm and perinuclear area. Therefore, the separation according to PC1 reflects the differing subcellular environments rather than the specific environment of polystyrene itself.

The loading of PC2, however, shows some indication of the characteristic polystyrene peaks, although PC2 does not differentiate the two KMCA clusters. Some biochemical signatures of 
lipids at $718 \mathrm{~cm}^{-1}$ (membrane lipids), $1065 \mathrm{~cm}^{-1}, 1088 \mathrm{~cm}^{-1}, 1304 \mathrm{~cm}^{-1}, 1439 \mathrm{~cm}^{-1}$ and 1656 $\mathrm{cm}^{-1}$ (Phospholipids) can be seen in the positive loading of PC2 while bands at $873 \mathrm{~cm}^{-1}$ and $1600 \mathrm{~cm}^{-1}$ indicates the presence of proteins. Moreover, the band at $1656 \mathrm{~cm}^{-1}$, indicating the presence of phospholipids in the biological content of the environment cluster, may be associated with the membrane derived structure of early endosomes. A sharp L- $\alpha$ phosphatidylcholine band at around $790 \mathrm{~cm}^{-1}$ is also observed in the negative loading of $\mathrm{PC} 2^{37}$.
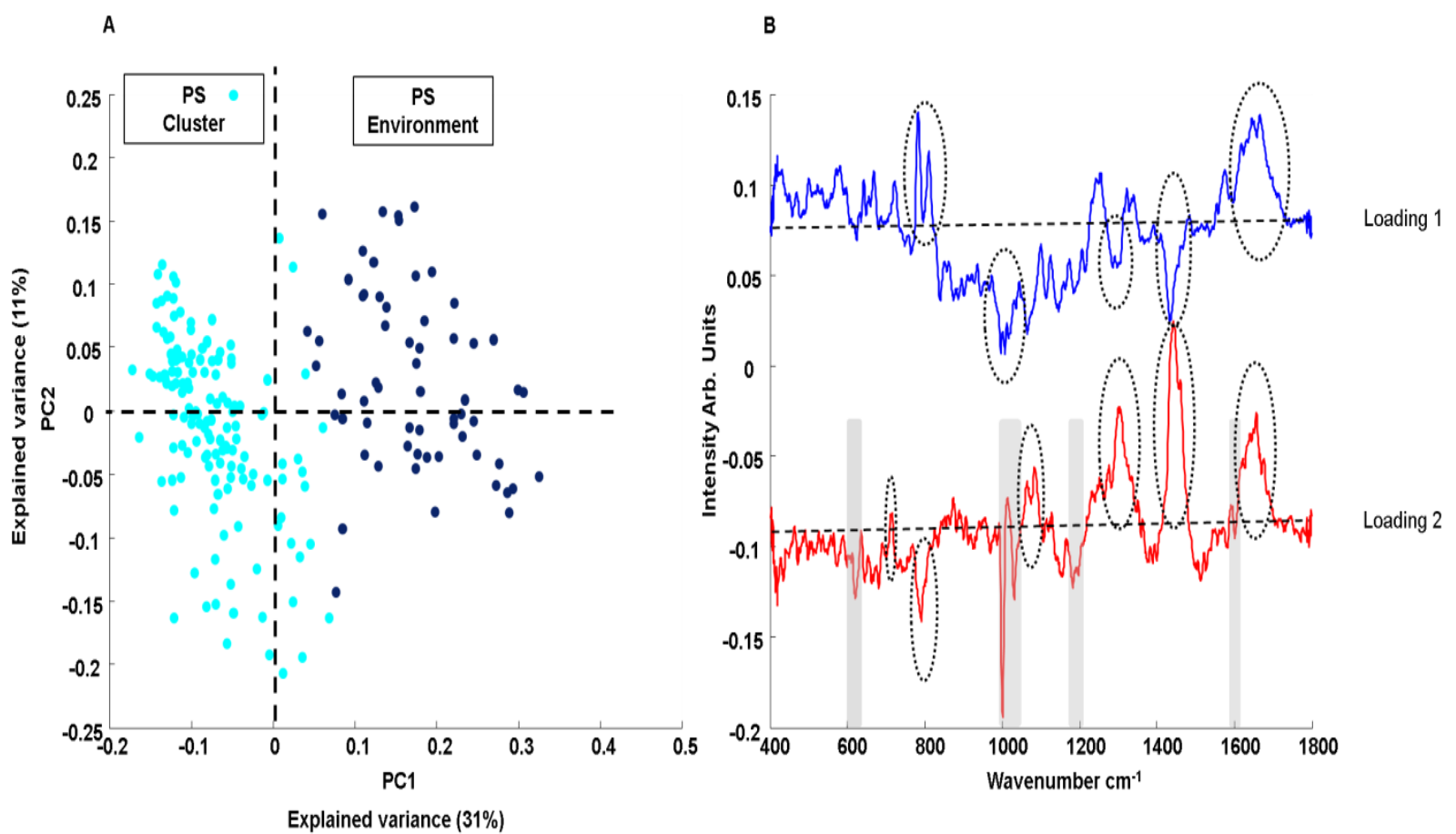

Figure 10. (A), Scatter plot of the PCA of spectra corresponding to the polystyrene cluster (Cluster 8, light blue) and polystyrene environment (Cluster 4, dark blue) for 4 hour particle exposure, before PS subtraction (B), Loading of PC1 and PC2 before PS subtraction.

When the size of early endosomes $(200-500 \mu \mathrm{m})$, the Raman source spot size and step size (1 $\mu \mathrm{m})$ are considered, contributions to each mapped spot of at least three different spectral profiles can be expected; that of polystyrene, early endosomes and the surrounding cytoplasm. Among these structures, the separation in spectra mainly arises from the 
biochemical differences of the cytoplasm and early endosomes, rather than the presence of polystyrene nanoparticles, due to the low signal from individual or small clusters of nanoparticles. The spectra of the polystyrene cluster identified by KMCA (Cluster 8) were therefore further analysed on their own using PCA. In the PCA scatter plot of Figure 11A, spectra are separated by both PC1 and PC2. Notably, the negative loading of PC2 is clearly dominated by the spectral features of polystyrene (Figure 11B, Loading 2), although some cellular molecular signatures are also present $\left(1158 \mathrm{~cm}^{-1}\right.$ related to proteins, $1180 \mathrm{~cm}^{-1}$ related to nucleic acids and $1439 \mathrm{~cm}^{-1}$ related to lipids). The positive loading of PC2 shows bands which can be attributed to the presence of nucleic acids $\left(\sim 785 \mathrm{~cm}^{-1}\right.$ and $810 \mathrm{~cm}^{-1}$ which are related to RNA and phosphodiester $\mathrm{Z}$ marker, respectively), and lipids $\left(1255 \mathrm{~cm}^{-1}\right)$. In order to further elucidate the spectral signatures of the underlying biochemical structure, the raw polystyrene spectrum was subtracted from the Polystyrene cluster. As seen in Figure 11C, the spectra are again distributed in all quadrants of the PC1/PC2 scatterplot. The loadings of PC1 and PC2 in Figure 11D contain the same biological features as that of the un-subtracted spectra in Figure 11B and, as the loading of PC2 in Figure 11B is differentiated according to polystyrene content, the loading of PC2 in Figure 11D is interpreted as the differentiation between early endosome (negative) and neighbouring cytoplasm (positive). Band assignments can be seen in detail in Table 5 . 

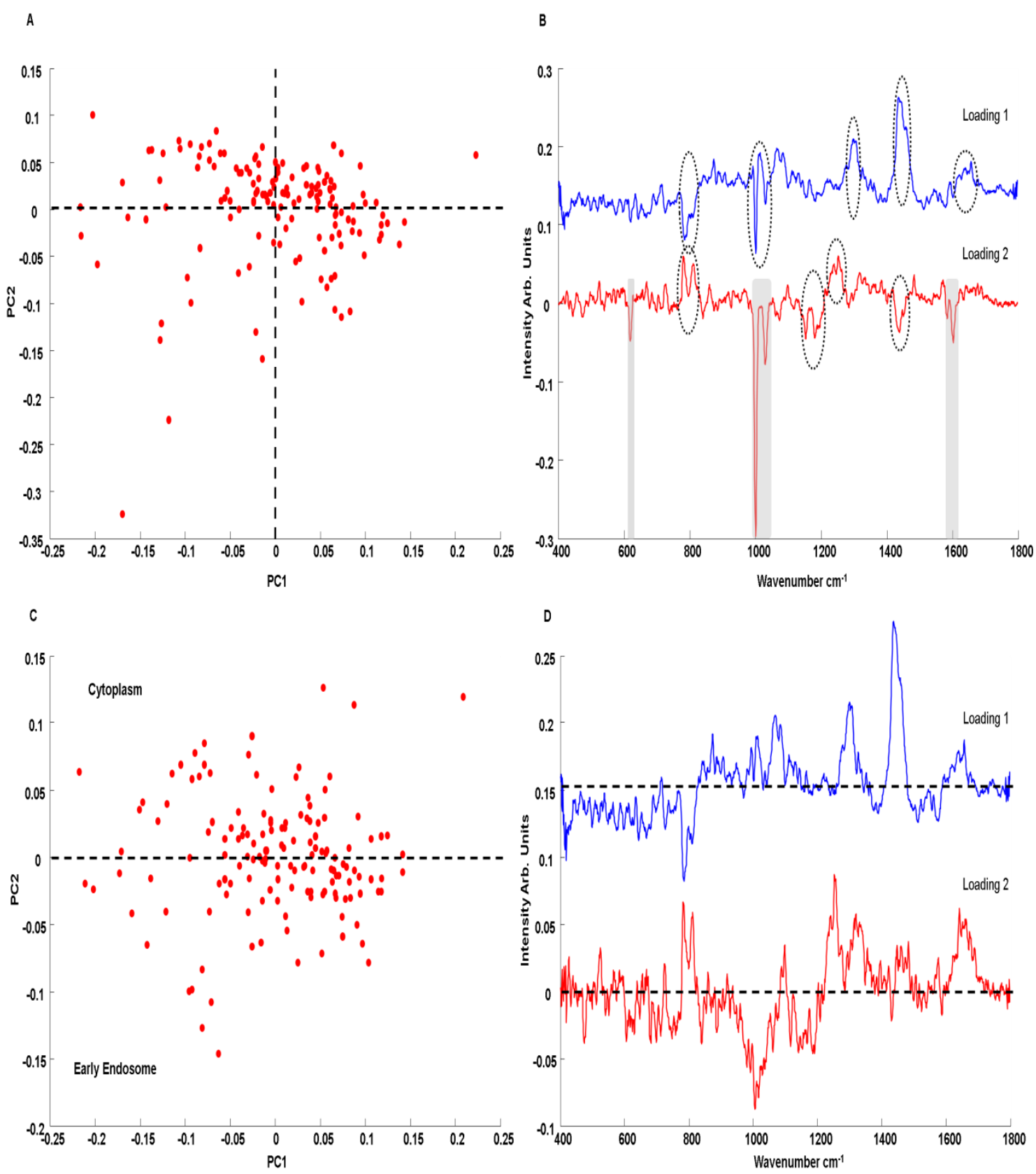

Figure 11. (A), Scatter plot of the PCA of spectra corresponding to the polystyrene cluster for 4 hour particle exposure (B), PC loadings of polystyrene cluster (C), Scatter plot of the PCA of spectra corresponding to the polystyrene cluster after polystyrene subtraction for 4 hour particle exposure (D), PC loadings of polystyrene subtracted polystyrene cluster. Spectra are offset for clarity. The dotted line represents the ' 0 ' line for each loading. 
In order to identify spectral differences between cytoplasm and early endosome, positively $(\mathrm{PC} 2 \geq 0)$ and negatively $(\mathrm{PC} 2<0)$ scored mean spectra related to PC2 (Figure 11C) were calculated as seen in Figure 12. When the mean spectra which are negatively and positively scored are subtracted from each other to show biochemical differences between early endosome and cytoplasm, similar features with Figure 11D- Loading 2 are obtained.

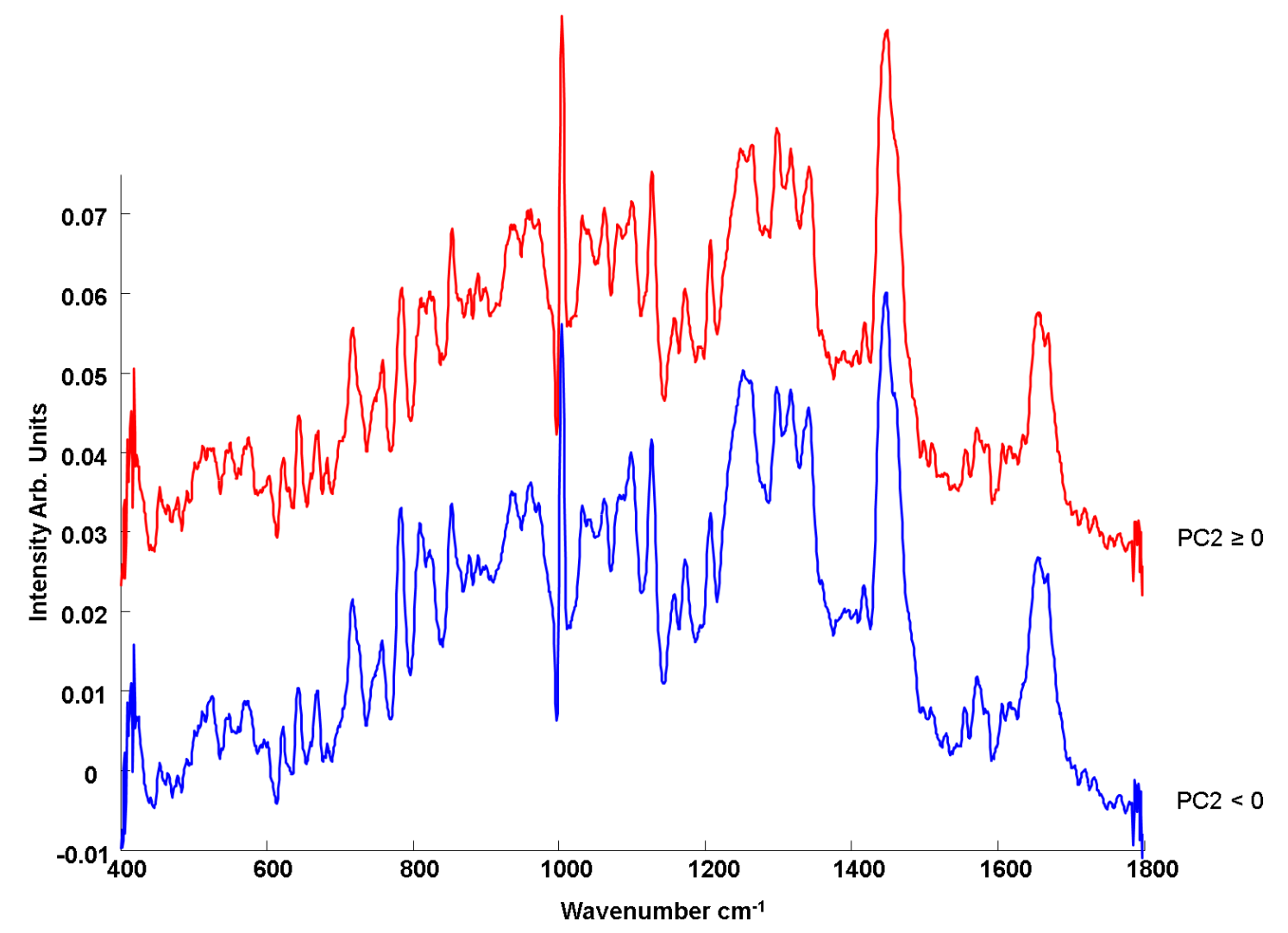

Figure 12. Mean spectra of cytoplasm (Loading of $P C 1 \geq 0$, red), early endosome (Loading of PC $1<0$, blue) after PC subtraction for 4 hour exposure and difference between mean spectra of cytoplasm and early endosome (green). Spectra are offset for clarity.

Briefly, the cytoplasm is differentiated from the early endosome by the bands at 785 and 810 $\mathrm{cm}^{-1}$ which are related to presence of nucleic acids. Also, spectra are differentiated by the 
band at $1237 \mathrm{~cm}^{-1}$, which can be attributed to Amide III band of proteins as a result of higher protein content in the cytoplasm compared to the early endosomes. On the other hand, early endosomes are differentiated from the cytoplasm by bands at 1066 and $1439 \mathrm{~cm}^{-1}$ which indicate the presence of lipids ${ }^{43-45}$.

Table 5. Band assignments related to polystyrene cluster and polystyrene environment after 4 hour particle exposure ${ }^{44-46}$.

\begin{tabular}{|c|c|c|}
\hline $\begin{array}{c}\text { Band Assignment } \\
\left(\mathrm{cm}^{-1}\right)\end{array}$ & $\begin{array}{c}\text { Polystyrene } \\
\text { Cluster }\end{array}$ & $\begin{array}{c}\text { Polystyrene } \\
\text { Environment }\end{array}$ \\
\hline 718 & - & Membrane Lipids \\
\hline 790 & L- $\alpha$-phosphatidylcholine & - \\
\hline 970 & Proteins & - \\
\hline 1031 & Proteins & Phosopholipids \\
\hline 1080 & - & Lipids \\
\hline 1304 & - & Phospholipids\& Proteins \\
\hline $1656-1600$ & - &
\end{tabular}

Finally, the extracted Raman spectral profiles associated with the underlying biochemical environment of the polystyrene nanoparticles for each exposure time, 24, 12, and 4 hrs, were compared, to demonstrate the applicability of Raman spectroscopy to determine and differentiate particle localisation within different subcellular compartments. Results showed that the extracted spectra and characteristics for different organelles are well differentiated, as seen in Figure 13A. The respective PC loadings which differentiated them from their immediate environment are shown in Figure 13B. According to the CLSM observations, nanoparticles are expected to be seen in endoplasmic reticulum, lysosomes and early endosomes, respectively, from longer to shorter exposure times. Therefore, the spectra for 24, 12 and $4 \mathrm{hr}$ may be associated with the spectrum of endoplasmic reticulum, lysosomes and 
early endosomes, which can be used as a guide to evaluate nanoparticle localisation with Raman spectroscopy.

Polystyrene nanoparticles are taken into cells by the process of endocytosis ${ }^{12}$, whereafter they are bound by membrane derived endosomal vesicles, as confirmed by the CLSM images after $4 \mathrm{hr}$ exposure. Considering the Raman spectrum related to $4 \mathrm{hr}$ particle exposure, strong bands in the spectral range between 700 and $900 \mathrm{~cm}^{-1}$ are observed in the mean spectra, compared to 12 and $24 \mathrm{hr}$ particle exposure. This region can be attributed to proteins which naturally exist in membrane structure ${ }^{44-46}$. Lipid and phospholipid related bands are also prominent in the spectra associated with early endosomes due to their membrane derived nature.

Following the particle exposure and uptake, early endosomes are internally trafficked and become engulfed by lysosomes. Lysosomes originate from the golgi apparatus, and therefore, as a biochemical structure, they show similar properties to the golgi apparatus or endoplasmic reticulum. Considering the Raman signature derived from the $12 \mathrm{hr}$ exposure data set, the PC loading is dominated by features of proteins and lipids. The signatures of both are significantly different to those associated with the early endosomes, however. In $12 \mathrm{hr}$ exposure test which relates to biochemical content of lysosomes, the bands at around 519, 759, 1130, 1304 and $1439 \mathrm{~cm}^{-1}$ are observed which are related to phosphatidylinositol, phosphatidylethanolamine, $\mathrm{C}-\mathrm{C}$ stretch of lipids, $\mathrm{CH}_{2}$ twist of lipids and $\mathrm{CH}_{\mathrm{def}}$ of lipids, respectively. On the other hand, for early endosomes, lipid bands showed more phospholipid related bands at around 1080 and $1656 \mathrm{~cm}^{-1}$ with phosphatidylcholine and membrane lipids at 790 and $718 \mathrm{~cm}^{-1}$, respectively. Compared to $4 \mathrm{hr}$ spectrum, the features in the $700-900 \mathrm{~cm}^{-1}$ region disappear, and clear differences can be observed in Amide I and Amide III regions. 
Lysosomes containing polystyrene nanoparticles are further trafficked to the golgi apparatus or endoplasmic reticulum ${ }^{15,48}$. The mean spectrum related to the endoplasmic reticulum shows prominent nucleic acid bands at $785 \mathrm{~cm}^{-1}$ and $810 \mathrm{~cm}^{-1}$, indicating the presence of RNA for protein synthesis around the perinuclear region and granular endoplasmic reticulum. Moreover, the prominence of protein and lipid related bands is consistent with the lipid and protein rich nature of the endoplasmic reticulum. The PC loading is also differentiated from that of $12 \mathrm{hr}$ exposure time by the bands around $718 \mathrm{~cm}^{-1}, 733 \mathrm{~cm}^{-1}$ which are related to membrane lipids, produced in the endoplasmic reticulum.
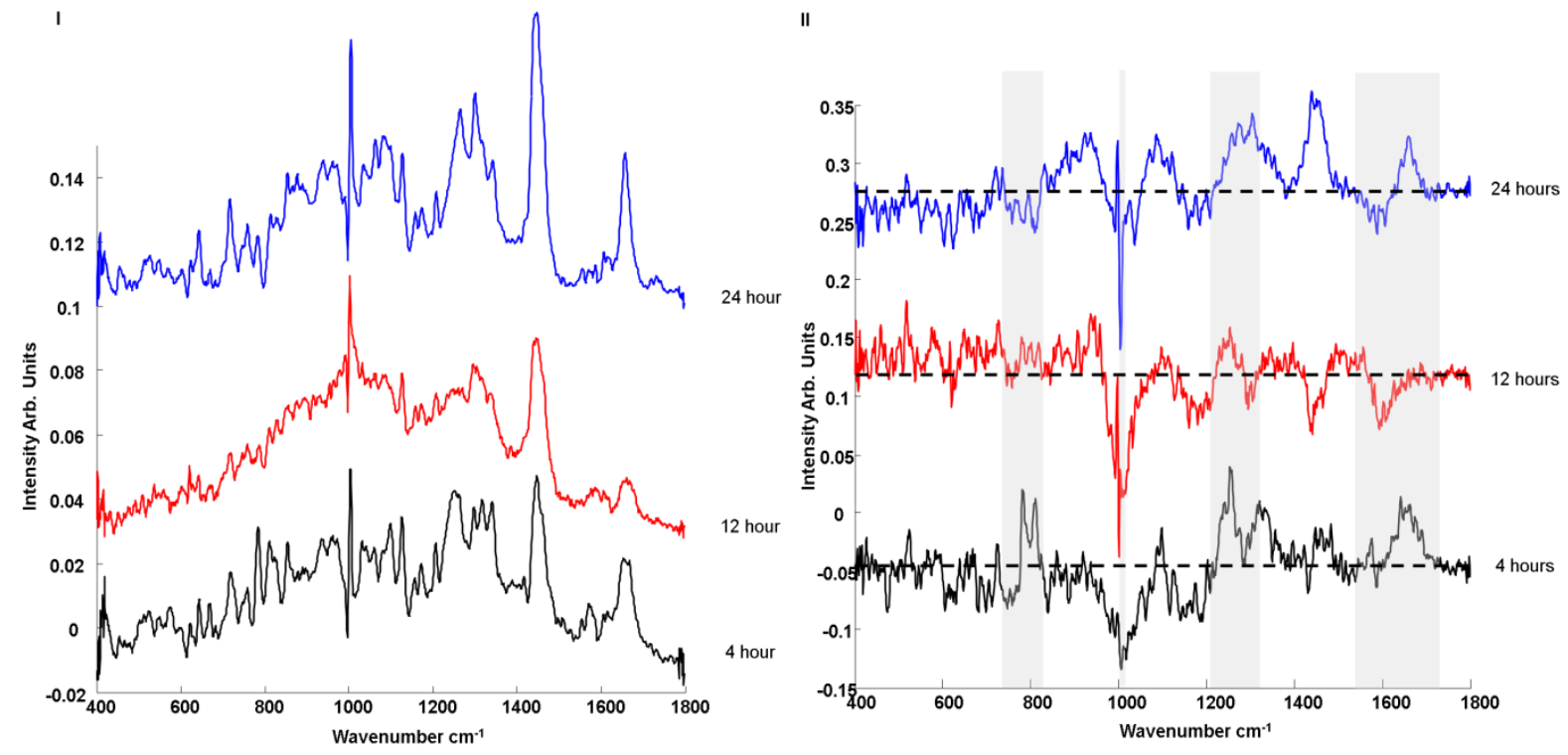

Figure 13. I ; Comparison of mean spectra of 4, 12 and 24 hour nanoparticle exposure data sets. II ; Comparison of PCA loadings of 4, 12 and 24 hour nanoparticle exposure data sets. The loadings of PC1 are used for 24 (Figure 4) and 12 hour (Figure 7) data sets while the loading of PC2 is used for the 4 hour data set (Figure 11). The main indicator bands for the different exposure time data sets were assigned according to Tables 3, 4 and 5. Spectra are offset for clarity. The dotted line represents the ' 0 ' line for each loading. 
One of the biggest and most consistent differences for the different exposure times is observed in the spectral range between $1585 \mathrm{~cm}^{-1}$ and $1660 \mathrm{~cm}^{-1} 43-45$. Raman bands in this region can be attributed to a number of distinct biochemical structures. They include the vibration of $\mathrm{C}=\mathrm{C}$ bond of phospholipids, $\mathrm{C}=\mathrm{O}$ bond of lipids and Amide $\mathrm{I}$ band of proteins ${ }^{44-}$ 46. However, proteins containing electron rich amino acid residues such as Phe, Tyr and Thr have a characteristic band at $1004 \mathrm{~cm}^{-1}$, due to the symmetric ring breathing. For the $4 \mathrm{hr}$ exposure data set, this broad band is observed at $1656 \mathrm{~cm}^{-1}$, which, coupled with the 1080 $\mathrm{cm}^{-1}$ phospholipid related band and no significant evidence of a protein band at $1004 \mathrm{~cm}^{-1}$, indicates the presence of phospholipids. On the other hand, the $12 \mathrm{hr}$ data set exhibits a strong band at $1004 \mathrm{~cm}^{-1}$ and therefore the band at around $1585-1600 \mathrm{~cm}^{-1}$ may be associated with the presence of proteins. For the $24 \mathrm{hr}$ exposure data set, the broad band in the spectral range between $1655-1680 \mathrm{~cm}^{-1}$ can therefore be attributed to lipids, due to absence of the band at around $1004 \mathrm{~cm}^{-1}$ band. The second notable differentiating band range is that of the Amide III region of proteins from $1231 \mathrm{~cm}^{-1}$ to $1284 \mathrm{~cm}^{-1}$, which shows the differences in protein secondary structures ${ }^{43-45}$.

Raman spectroscopy, with the aid of multivariate analysis, can therefore clearly be used to not only identify the presence of nanoparticles within cells, based on their chemical signatures, but also explore the local environment, identifying different spectroscopic signatures of that environment as the nanoparticles are progressively trafficked through the cell. The study demonstrates the principle based on analysis of individual cells at each timepoint, although over the course of the study, multiple cells were analysed at each time-point, representative examples being shown here. The CLSM analysis, consistent with literature, demonstrates that the subcellular processes are uniform within a cell culture, and indeed a general phenomenon in vitro. 
It is noted, however, than while organic polymeric nanoparticles have distinctive spectra with features spanning the fingerprint region, inorganic nanoparticles may not have as rich spectra which can be used for identification purposes. For example, silica nanoparticles have relatively few distinguishing bands and furthermore their vibrational properties can be affected by the formation of lattice like structure due to hydrogen bonds between $\mathrm{SiOH}$ groups within neighbouring silica nanoparticles ${ }^{49}$. Iron Oxide nanoparticles are also renowned for their weak Raman spectrum in the fingerprint region ${ }^{50}$. However, the weak signal of inorganic nanoparticles can be increased by the use of Raman reporter molecules and preparation of bio-composites or core-shell structures of inorganic nanoparticles. In order to overcome the lattice formation problems in silica nanoparticles, the use of organosilane compounds and the effect of vacuum drying of the samples have been shown in the study of Volovsek et. al. ${ }^{51}$. Semiconductor quantum dots are often functionalised for biological applications with coatings such as poly ethylene glycol (PEG), PEG-amines or carboxylic acids, and may therefore also be identified by the Raman signature of the coating, although this may challenge the sensitivity of the technique ${ }^{52-54}$.

\section{Conclusion}

The study showed the applicability of Raman spectroscopy to determine the localisation of nanoparticles within cellular compartments, based on their intrinsic chemical structures without labelling at different incubation times. The study also demonstrates the power of Raman spectroscopy with different multivariate analysis techniques to extract biochemical information from intracellular compartments as a non-invasive and completely label free technique. Spectral differences between nanoparticles and their environment were analysed and spectral features related to endoplasmic reticulum, lysosome and early endosome were 
investigated at different particle exposure times. Although the data aquistion speed is currently somewhat slow, improved system performance and sensitivities will enable more rapid and ultimately realtime monitoring, towards the realisation of Raman spectroscopy as a label free, high content analysis technique for in vitro screening of toxicity and drug efficacy.

\section{Acknowledgement:}

This work was supported by Science Foundation Ireland Principle Investigator Award 11/PI/1108.

\section{Conflict of Interest:}

The authors declare that there are no conflicts of interest. 


\section{References}

1. K. Donaldson, V. Stone, C. L. Tran, W. Kreyling, P. J. Borm, Occup. Environ. Med., 2004, 61, 727-728.

2. J. Curtis, M. Greenberg, J. Kester, S. Phillips, G. Krieger, Toxicol. Sci., 2006, 25, 245-260.

3. A. V. Kabanov, Adv. Drug. Deliv. Rev., 2006, 58, 1597-1621.

4. K. E. Driscoll, J. M. Carter, B. W. Howard, D.G. Hassenbein, W. Pepelko, R. B. Baggs, G. Oberdoerster, Toxicol. Appl. Pharmacol., 1996, 136, 372-380.

5. P. Naha, H. J. Byrne, Aquatic Toxicology, 2013, 132-133, 61-72.

6. M. D. Englen, S. M. Taylor, W. W. Laegreid, R. M. Silflow, R. W. Leid, Exp. Lung. Res., 1990, 16, 691-709.

7. N. Lewinski, V. Colvin, R. Drezek, Small, 2008, 4, 26-49.

8. C. S. Yah, G. S. Simate, S. E. Iyuke, Pak. J. Pharm. Sci., 2012, 25, 477-491.

9. S. Lanone, J. Boczkowski, Curr. Mol. Med., 2006, 6, 651-663.

10. A. Nel, T. Xia, L. Madler, N. Li, Science, 2006, 311, 622-627.

11. L. Treuel, X. Jiang, G.U. Nienhaus, J. R. Soc. Interface, 2013, 10, 20120939.

12. A. Salvati, C. Aberg, T. Dos Santos, Nanomedicine: nanotechnology, biology, and medicine, 2011, 7, 818-826.

13. K. Shapero, F. Fenaroli, I. Lynch, D.C. Cottell, A. Salvati, K. A. Dawson, Molecular Biosystems, 2011, 7, 371-378.

14. Q. Mu, N. S. Hondow, L. Krzemiński, A. P. Brown, L. J. Jeuken, M. N. Routledge, Part. Fibre. Toxicol., 2012, 23, 9-29.

15. J. Dorney, F. Bonnier, A. Garcia, A. Casey, G. Chambers, H. J. Byrne, Analyst, 2012, 137, 1111-1119.

16. M. Keating, F. Bonnier, H. J. Byrne, Analyst, 2012, 137, 5792-5802.

17. M. Keating, H. J. Byrne, NanoMedicine, 2013, 8, 1335-1351.

18. M. Davoren, E. Herzog, A. Casey, B. Cottineau, G. Chambers, H. J. Byrne, F. M. Lyng, Toxicology in Vitro, 2007, 21, 438-448.

19. P. Sandin, L. W. Fitzpatrick, J. C. Simpson, K. Dawson, ACS nano, 2012, 6, 1513-1521.

20. F. Fazlollahi, S. Angelow, N. R. Yacobi, Nanomedicine: nanotechnology, biology, and medicine, 2011, 7, 588-594.

21. E. Jan, S. J. Byrne, M. Cuddihy, ACS nano, 2008, 2, 928-938.

22. J. Pawley, Handbook of biological confocal microscopy $3^{\text {rd }}$ ed., Springer-Verlag, Heidelberg, 2006.

23. L. Aparicio-Ixta, G. Ramos-Ortiz, J. L. Pichardo-Molina, Nanoscale, 2012, 4, 7751-7759.

24. Y. Yang, F. An, Z. Liu, Biomaterials, 2012, 33, 7803-7809.

25. T. T. Le, H. M. Duren, M. N. Slipchenko, C. D. Hu, J. X. Cheng, Journal of Lipid Research, 2010, 51, 672-677.

26. H. Suh, B. Jeong, F. K. S. Liu, Pharm. Res., 1998, 15, 1495-1498.

27. C. Matthaus, T. Chernenko, J. A. Newmark, C. M. Warner, M. Diem, Biophysical Journal, 2007, 93, 668-673.

28. P. R. Carey, Biochemical Applications of Raman and Resonance Raman Spectroscopies. Academic Press, New York, 1982.

29. E. C. Mattson, E. Aboualizadeh, M. E. Barabas, C. L. Stucky, C. J. Hirschmugl, Int. J. Mol. Sci., 2013, 14, 22753-22781.

30. J. Li, R. Strong, J. Trevisan, S. W. Fogarty, N. J. Fullwood, K. C. Jones, F. L. Martin, Environ. Sci. Technol., 2013, 47, 10005-10011. 
31. S. Rhiem, M. J. Riding, W. Baumgartner, F. L. Martin, K. T. Semple, K. C. Jones, A. Schaffer, H. M. Maes, Environmental Pollution, 2015, 196, 431-439.

32. J. Li, G. Ying, K. C. Jonesa, F. L. Martin, Analyst, 2015, 140, 2687-2695.

33. F. Draux, P. Jeannesson, A. Beljebbar, A. Tfayli, N. Fourre, M. Manfait, J. Sule-Suso, G. D. Sockalingum, Analyst, 2009, 134, 542-548.

34. M. Miljkovic, T. Chernenko, M. J. Romeo, B. Bird, C. Matthaus, M. Diem, Analyst, 2010, 135, 2002-2013.

35. H. Nawaz, F. Bonnier, P. Knief, O. Howe, F. M. Lyng, A. D. Meade, H. J. Byrne, Analyst, 2010, 135, 3070-3076.

36. K. Klein, A. M. Gigler, T. Aschenbrenner, R. Monetti, W. Bunk, F. Jamitzky, G. Morfill, R. W. Stark, J. Schlegel, Biophys J., 2012, 102, 360-368.

37. S. D. Krauss, D. Petersen, D. Niedieker, I. Fricke, E. Freier, S. F. El-Mashtoly, K. Gerwert, A. Mosig, Analyst, 2015, 140, 2360-2368.

38. Thermofisher Scientific (2015) Molecular Probes, http://tools.thermofisher.com/content/sfs/manuals/mp05000.pdf. Accessed 07 October 2015.

39. J. Dorney, Polystyrene: A Potential Standard For Developing In Vitro Cellular Tracking Methods For Nanotoxicology. PhD, Dublin Institute of Technology, 2013.

40. S. Bolte, F. P. Cordelieres, Journal of Microscopy, 2006, 224, 213-232.

41. F. Bonnier, A. Mehmood, P. Knief, A. Meade, W. Hornebeck, H. Lambkin, K. Flynn, V. McDonagh, C. Healy, T. C. Lee, F. M. Lyng, H. J. Byrne, Journal of Raman Spectroscopy, 2011, 42, 888-896.

42. F. Bonnier, P. Knief, B. Lim, A. D. Meade, J. Dorney, K. Bhattacharya, F. M. Lyng, H. J. Byrne, Analyst, 2010, 135, 3169-3177.

43. I. Notingher, S. Verrier, S. Haque, J. M. Polak, L. L. Hench, Biopolymers (Biospectroscopy), 2003, 72, 230-240.

44. I. Notingher, L. L. Hench, Expert Rev. Med. Devices, 2006, 3, 215-234.

45. Z. Movasaghi, S. Rehman, I. U. Rehman, Applied Spectroscopy Reviews, 2007, 42, 493-541.

46. M. Terasaki, L. A. Jaffe, J. Cell Biol., 1991, 114, 929-940.

47. W. Kuehnel, Color atlas of Cytology, Histology, and Microscopic Anatomy, Thieme, Germany, 2003.

48. M. Y. Chang, A. L. Shiau, Y. H. Chen, C. J. Chang, H. H. Chen, C. L. Wu, Cancer Sci., 2008, 99, 1479-1484.

49. C Meier, S Lüttjohann, VG Kravets, H Nienhaus, A Lorke, H Wiggers, Physica E, 2006, 32, 155-158.

50. Madhavi, T.N.V.K.V. Prasad, G. Madhavi, International Journal of Nanomaterials and Biostructures, 2013, 3, 31-34.

51. V. Volovšek, V., K. Furić, L. Bistričić, M. Leskovac, Macromol. Symp. 2008, 265, 178-182.

52. L. Lu, XL. Xu, WT. Liang, HF. Lu, J. Phys., Condens. Matter, 2007, 19, 406221.

53. S. J. Byrne, S. A. Corr, T. Y. Rakovich, Y. K. Gun'ko, Y. P. Rakovich, J. F. Donegan, S. Mitchell, Y. Volkov, J. Mater. Chem. 2006, 16, 2896 - 2902.

54. J. Lee, J. Kim, E. Park, S. Jo, R. Song, Phys Chem Chem Phys., 2008, 10, 1739-42. 